\title{
Quadrupole Ion Trap Mass Spectrometer for Ice Giant Atmospheres Exploration
}

\author{
J. Simcic ${ }^{1}$ D D. Dikolić ${ }^{1}$ • A. Belousov ${ }^{1}$ • D. Atkinson ${ }^{1}$ • \\ C. Lee ${ }^{1} \cdot$ S. Madzunkov ${ }^{1} \cdot$ D. Almodiel ${ }^{2}$
}

Received: 16 March 2020 / Accepted: 21 December 2020 / Published online: 18 January 2021 (C) This is a U.S. government work and not under copyright protection in the U.S.; foreign copyright protection may apply 2021

\begin{abstract}
To date, a variety of different types of mass spectrometers have been utilized on missions to study the composition of atmospheres of solar system bodies, including Venus, Mars, Jupiter, Titan, the moon, and several comets. With the increasing interest in future small probe missions, mass spectrometers need to become even more versatile, lightweight, compact, and sensitive.

For in situ exploration of ice giant atmospheres, the highest priority composition measurements are helium and the other noble gases, noble gas isotopes, including ${ }^{3} \mathrm{He} /{ }^{4} \mathrm{He}$, and other key isotopes like $\mathrm{D} / \mathrm{H}$. Other important but lower priority composition measurements include abundances of volatiles $\mathrm{C}, \mathrm{N}, \mathrm{S}$, and $\mathrm{P}$; isotopes ${ }^{13} \mathrm{C} /{ }^{12} \mathrm{C},{ }^{15} \mathrm{~N} /{ }^{14} \mathrm{~N},{ }^{18} \mathrm{O} /{ }^{17} \mathrm{O} /{ }^{16} \mathrm{O}$; and disequilibrium species $\mathrm{PH}_{3}, \mathrm{CO}, \mathrm{AsH}_{3}, \mathrm{GeH}_{4}$, and $\mathrm{SiH}_{4}$. Required measurement accuracies are largely defined by the accuracies achieved by the Galileo (Jupiter) probe Neutral Mass Spectrometer and Helium Abundance Detectors, and current measurement accuracies of solar abundances.

An inherent challenge of planetary entry probe mass spectrometers is the introduction of material to be sampled (gas, solid, or liquid) into the instrument interior, which operates at a vacuum level. Atmospheric entry probe mass spectrometers typically require a specially designed sample inlet system, which ideally provides highly choked, nearly constant mass-flow intake over a large range of ambient pressures. An ice giant descent probe would have to operate for 1-2 hours over a range of atmospheric pressures, possibly covering 2 or more orders of magnitude, from the tropopause near 100 mbar to at least $10 \mathrm{bars}$, in an atmospheric layer of depth beneath the tropopause of about $120 \mathrm{~km}$ at Neptune and about $150 \mathrm{~km}$ at Uranus.

The Jet Propulsion Laboratory's Quadrupole Ion Trap Mass Spectrometer (QITMS) is being developed to achieve all of these requirements. A compact, wireless instrument with a
\end{abstract}

In Situ Exploration of the Ice Giants: Science and Technology

Edited by Olivier J. Mousis and David H. Atkinson

\section{J. Simcic}

1 Jet Propulsion Laboratory, California Institute of Technology, 4800 Oak Grove Dr., Pasadena, CA 91109, USA

2 Department of Electrical \& Computer Engineering, Hampton University, 130 William R. Harvey Way, Hampton, VA 23668, USA 
mass of only $7.5 \mathrm{~kg}$, and a volume of 7 liters (7U), the JPL QITMS is currently the smallest flight mass spectrometer available for possible use on planetary descent probes as well as small bodies, including comet landers and surface sample return missions. The QITMS is capable of making measurements of all required constituents in the mass range of 1-600 atomic mass units (u) at a typical speed of 50 mass spectra per second, with a sensitivity of up to $10^{13}$ counts $/ \mathrm{mbar} / \mathrm{sec}$ and mass resolution of $m / \Delta m=18000$ at $\mathrm{m} / \mathrm{q}=40$. (Throughout this paper we use the unit of $\mathrm{m} / \mathrm{q}=\mathrm{u} / \mathrm{e}$ for the mass-to-charge ratio, where atomic mass unit and elementary charge are $1 \mathrm{u}=1.66 \times 10^{-27} \mathrm{~kg}$ and $1 \mathrm{e}=1.6 \times 10^{-19} \mathrm{C}$, respectively.) The QITMS features a novel MEMS-based inlet system driven by a piezoelectric actuator that continuously regulates gas flow at inlet pressures of up to $100 \mathrm{bar}$.

In this paper, we present an overview of the QITMS capabilities, including instrument design and characteristics of the inlet system, as well as the most recent results from laboratory measurements in different modes of operation, especially suitable for ice giant atmospheres exploration.

Keywords Quadrupole ion trap · Mass spectrometer · Noble gases · Atmospheric descent

\section{Introduction}

Space exploration has been a driving force in developing cutting edge technologies over the past several decades. To expand our knowledge about the formation and evolution of the solar system, exploration of solar system bodies and environments require instruments to make precise measurements with data relayed back to Earth for analysis and interpretation. Mass spectrometers (MS) hold a prominent role among spaceflight instruments, performing in-situ measurements of the composition of both rocky and gaseous environments to help illuminate the origin and evolution of the body. Noble gas abundances and isotopic ratios, in particular, provide an important means of discriminating between competing theories of the origin and evolution of the entire solar system (see Mousis and Atkinson 2021, this journal).

Space missions making some of the earliest in-situ measurements of planetary atmospheres include the Pioneer Venus probes Fimmel et al. (1983), Spencer (1974), Hoffman (1974), Mars Viking Landers Anderson et al. (1972), Biemann (1974), Biemann et al. (1977), the Galileo Jupiter Probe Niemann et al. (1998) and the European Space Agency Cassini Huygens Saturn Probe Niemann et al. (2005). Additionally, in the early years of space exploration, mass spectrometers were used to monitor volatile organic compounds in the cabin air on crewed missions, with cabin's air measurements telemetered back to Earth for analysis. For example, the Volatile Organic Analyzer, launched in 2001, an ion mobility spectrometer coupled to a gas chromatograph, successfully measured volatile organic content (VOC) on the International Space Station (ISS) Limero et al. (2003), Limero and James (2007) for 8 years. At the same time, the Vehicle Cabin Air Monitor (VCAM) Chutjian et al. (2007, 2008), developed by the Jet Propulsion Laboratory (JPL), utilized a miniature Quadrupole Ion Trap Mass Spectrometer (QITMS) to allow for continuous cabin air major constituents analysis in addition to a VOC measurement performed once a day. Recent state-of-the-art upgrades to VCAM are currently undergoing technological demonstration onboard the International Space Station as the Spacecraft Atmosphere Monitor Madzunkov et al. (2017). Whether for monitoring cabin air on crewed missions or determining the composition of planetary atmospheres and bodies, the flight mass spectrometers share the common requirements of low mass, constrained volume, low power, and high reliability. 
The formation, evolution, and current structure of the solar system, including the location and properties of the terrestrial planets, has been largely affected by the giant planets Gomes et al. (2005), including possible delivery of volatiles to Earth and the other terrestrial planets Chambers and Wetherill (2001), Chambers (2001). Understanding the conditions within the protosolar nebula at the location and epoch of giant planet formation, and the processes by which the giant planets formed, is therefore key to both understanding the evolution and ultimate structure of the solar system as well as lending insight into the observed structure of exoplanetary systems (see Atreya et al. (2016) and references therein).

The composition is singularly the most important characteristic of giant planet atmospheres and interiors. The Galileo atmospheric probe measured the chemical and isotopic composition of Jupiter's atmosphere, representing a major advance in understanding the origin of Jupiter and the Jupiter system Owen et al. (1999), Gautier et al. (2001). High accuracy measurements of the helium abundance on Jupiter were made by the Galileo probe and revealed enrichments (relative to solar) of noble gases argon, krypton, and xenon Mousis et al. (2014). The Galileo probe additionally measured the ratio of ${ }^{15} \mathrm{~N} /{ }^{14} \mathrm{~N}$ in the atmosphere, a strong indication that Jupiter's atmospheric nitrogen came directly from the protosolar nebula in the form of $\mathrm{N}_{2}$ Owen et al. (2001). More recently, the Cassini orbiter studied Saturn's upper atmosphere, ring system and moons, magnetosphere, and gravitational field. However, measurements of Saturn's deeper, well-mixed atmospheric composition, including abundances of noble gases and noble gas isotopes, disequilibrium species, other key isotopes, and condensables, must be made in situ by an atmospheric probe and were not part of Cassini's mission. Although several Saturn entry probe missions have been proposed, to date, no in-situ missions to measure Saturn's atmospheric composition have been selected for flight Mousis et al. (2014), Spilker et al. (2011, 2012), Atkinson et al. (2012), Venkatapathy et al. (2012), Atkinson et al. (2013, 2014), Mousis et al. (2016), Atkinson et al. (2016).

Filling the size gap between the smaller terrestrial planets of the inner solar system and the gas giants, are the very distant ice giant planets. Neptune and Uranus are very different from either the terrestrial planets or the gas giants, and represent a class of planets that, to date, is largely unexplored. Except for methane $\left(\mathrm{CH}_{4}\right)$ and the recent detection from Earth of gaseous hydrogen sulfide $\left(\mathrm{H}_{2} \mathrm{~S}\right)$ spectral absorption features by Irwin, et al. Irwin et al. (2018, 2019a,b), no measurements have been made of the other key condensable species, such as ammonia $\left(\mathrm{NH}_{3}\right)$ and water $\left(\mathrm{H}_{2} \mathrm{O}\right)$, expected to be the primary constituents of clouds located in the Uranus and Neptune atmospheres, much deeper than can be reached by descent probes.

Many key properties of ice giant systems can be accessed by spacecraft remote observations, including cloud-top atmospheric constituents, dynamics, and processes. However, abundance measurements of atmospheric noble gases, noble gas isotopes, and other key isotopes require in-situ sampling. Noble gas abundances and noble gas isotope ratios are diagnostic of the physico-chemical state of the protosolar nebula at the time and epoch of giant planet formation. The bulk abundances of elemental species in the deeper atmosphere, are indicators of the mechanism by which additional heavy elements were delivered to all the planets Mousis et al. (2018). Detection of disequilibrium species and measurement of their abundances would reflect deep atmospheric chemistries and would help constrain the magnitude of atmospheric vertical mixing.

Since the noble gases and many isotope ratios are expected to be well-mixed, representative measurements can be made by a relatively shallow probe at any location on the planet. However, condensable species form cloud layers at depths depending both on the species' abundance and the thermal structure of the atmosphere, with ice giant cloud layers in the colder outer solar system expected much deeper in the atmosphere than found at warmer 
Jupiter and Saturn. Measurement of the well-mixed $\mathrm{NH}_{3}$ and $\mathrm{H}_{2} \mathrm{O}$ abundances and the altitude profile of disequilibrium species abundances would require probes to many 100's of bars, far beyond the capabilities of current technologies.

During a planetary atmospheric entry and descent probe mission, the time available to perform in-situ measurements is generally short due to a variety of factors inherent to atmospheric probe missions, including the limited time available for the probe to transmit data to the carrier relay spacecraft; the effect on the probe telecommunications link of increasing atmospheric attenuation, as the probe descends deeper into the atmosphere; limited battery resources; and possibly the effects of increasing pressure and temperature. For measurements in such demanding conditions, it is therefore of greatest importance to utilize an instrument with the highest possible sensitivity maintained under variable pressure conditions.

Abundance measurements of minor constituents requiring long integration times, are especially challenging. Mass spectrometers largely employ a non-discriminatory electron impact ionization of sampled gas mixtures for creating ions, which means the probability of creating and trapping ion fragments of trace species is very low, compared to the dominant ones. For example, the composition of the Venusian atmosphere is more than $96 \%$ carbon dioxide, while abundances of several key minor constituents, including noble gases, can be as few as several ppb, possibly with compositions that vary with altitude Krasnopolsky (2006). At Jupiter, the abundances of krypton and xenon measured by the Galileo probe are $(4.65 \pm 0.85) \times 10^{-9}$ and $(4.45 \pm 0.85) \times 10^{-10}$, respectively (Atreya et al. (2020), Table 1). Similarly, noble gas abundances in the atmospheres of the ice giants are expected to be in the ppb to sub-ppb range and present a similar challenge to measure accurately.

Mass spectrometers can only operate up to certain maximum internal pressure (usually in $10^{-6}-10^{-4}$ mbar region), before the space-charge effects start affecting the quality of the mass spectra, or damage is caused to their charged particle detectors. In the case of the QITMS, if the total number of confined ions exceeds $10^{5}$ per second, their mutual Coulomb repulsion causes the destabilization of ion trajectories, which results in ions colliding with the walls of the electrodes. Shortly after the contact with a metal surface, such ions become neutral molecules and cannot be extracted from the ion trap, which is a prerequisite for their detection.

To accurately measure the amount of trace species, one has to find ways to increase their proportion in the ion population by selective removal of the dominant species, while keeping the total number of trapped molecules below the maximum number. One solution, regularly employed in the case of noble gas measurements, is enrichment cells. These are dedicated sample volumes, evacuated with getter pumps, which remove all constituents, except methane and noble gases, from the mixture, before admitting it into the mass spectrometer. If one or more of the remaining components are still 3 or more magnitudes higher in abundance than the others (like argon extracted from Earth's atmosphere or methane in the case of ice giants), further operating techniques are employed to lower their presence in the MS. In this paper, we describe two, the low mass cut-off and selective resonant ejection of trapped ions, that can both eliminate major constituents of choice from an ion population, to allow the measurement of minor species abundances with a significant increase in accuracy. These two measuring techniques can be employed separately or together and with or without using the enrichment cells on any gas mixture.

\section{Instrument Overview}

The JPL QITMS Madzunkov et al. (2013) sensor is shown in Fig. 1. It consists of three isolated electrodes with hyperbolic interior surfaces: two end-cap (EC) electrodes (top-cap TC 
Fig. 1 Schematic view of the JPL QITMS sensor design featuring a z-stack microchannel plate detector

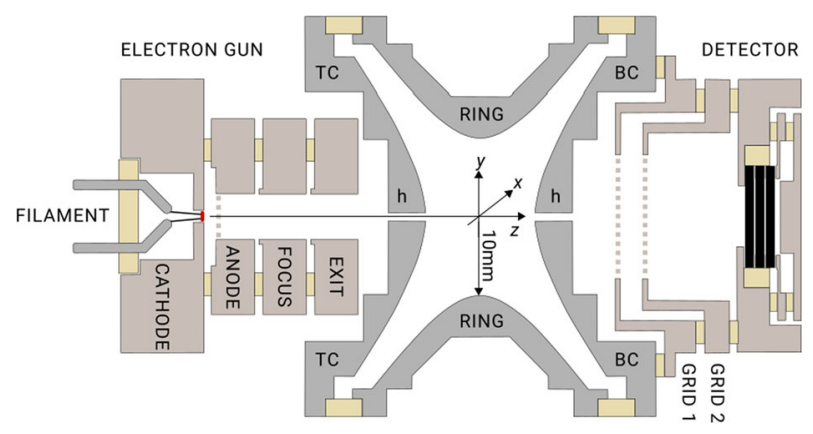

and bottom-cap BC) and a ring electrode in between. Both end-cap electrodes have cylindrical holes (h) in the center along the z-axis. One of them, (TC) holds the electron gun assembly. The other end-cap electrode (BC) holds the detector assembly. The hole (h) in the TC allows the electron beam, emitted by the electron gun, to reach the trapping volume. The hole in the $\mathrm{BC}$ allows ejection of the ions from the trapping volume and subsequent recording by the detector. In the simplest mode of operation, the two caps are grounded, while an $\mathrm{RF}$ signal of varying amplitude is connected to the ring electrode. The electron gun consists of the filament and four electrodes: the cathode, followed by the anode, the focus and the exit electrode. The latter three form a three-electrode lens of the Einzel type along the z-axis with the electrode aperture-to-length (A/D) ratio of 1 . The filament is a tantalum disc (Kimball Physics, model number ES-042) powered in current mode with $\sim 1.5 \mathrm{~A}$, with a thermal energy spread of less than $0.5 \mathrm{eV}$. The exit electrode is grounded, and the focus electrode potential defines the shape of the electron beam. The cathode holder is set at $-70 \mathrm{~V}$, which defines the electron energy. The anode electrode potential is pulsed from $0 \mathrm{~V}$ to $-\mathrm{Va}(\sim-$ $90 \mathrm{~V}$ ) to control the electron beam admittance into the QIT interior (Fig. 2). The detector assembly consists either of three micro channel plates arranged in a z-stack configuration or a channeltron (Magnum 5901), used as an electron multiplier, protected by two grids placed in front of it (Fig. 1). Grid potentials are pulsed from $0 \mathrm{~V}$ to $\mathrm{Vg}(+100 \mathrm{~V})$ for grid 1 to repel ions and from $0 \mathrm{~V}$ to $-\mathrm{Vg}(-100 \mathrm{~V})$ for grid 2 to repel electrons during the electron impact ionization phase, as shown in Fig. 2.

The QIT operates by repeating the duty cycle shown in Fig. 2. The RF potential of constant frequency $(0.8-\sim 1.5 \mathrm{MHz})$ is applied to the central ring electrode and has three distinct phases: ionization, cooling and ejection, respectively. During the ionization and cooling phases $\left(0.5 \mathrm{~ms}<\tau_{i}+\tau_{c}<25 \mathrm{~ms}\right)$ the RF amplitude is kept constant at the value, which is sufficient to trap ionized species of interest inside the QIT (typically 50-200 V). The ionization phase starts after a short delay (typically $\tau_{d} \sim 1 \mathrm{~ms}$ ) after the initial pulsing of the grids from $0 \mathrm{~V}$ to $\pm \mathrm{Vg}$. The anode electrode is raised from $-\mathrm{Va}$ to the ground potential, and consequently, the electron beam is admitted into the trapping volume. This phase lasts for a few milliseconds, after which, the anode's potential is set to - Va again. After another $1 \mathrm{~ms}$ of delay, the two grids are set back to the ground potential. During the ionization phase, ions are created along the line of the electron beam via electron impact ionization, the majority of them inside the central part of the $16.3 \mathrm{~cm}^{3}$ trapping volume. During that period, the detector is protected from an excessive number of charged particles by the raised grids. The cooling period allows trapped ions inside the QIT, which now move along trajectories that have an appearance of a Lissajous or Bowditch curve March (1997), to stabilize and cool down via collisions with the rest gas. This phase is especially important for the ion traps that utilize auxiliary cooling buffer gas $\left(\mathrm{H}_{2}\right.$ or $\left.\mathrm{He}\right)$ to achieve the required mass resolution 
Fig. 2 Duty cycle of the QITMS showing two modes $(a, b)$ of resonant excitation amplitudes of the auxiliary oscillating (dipole) field applied to the EC

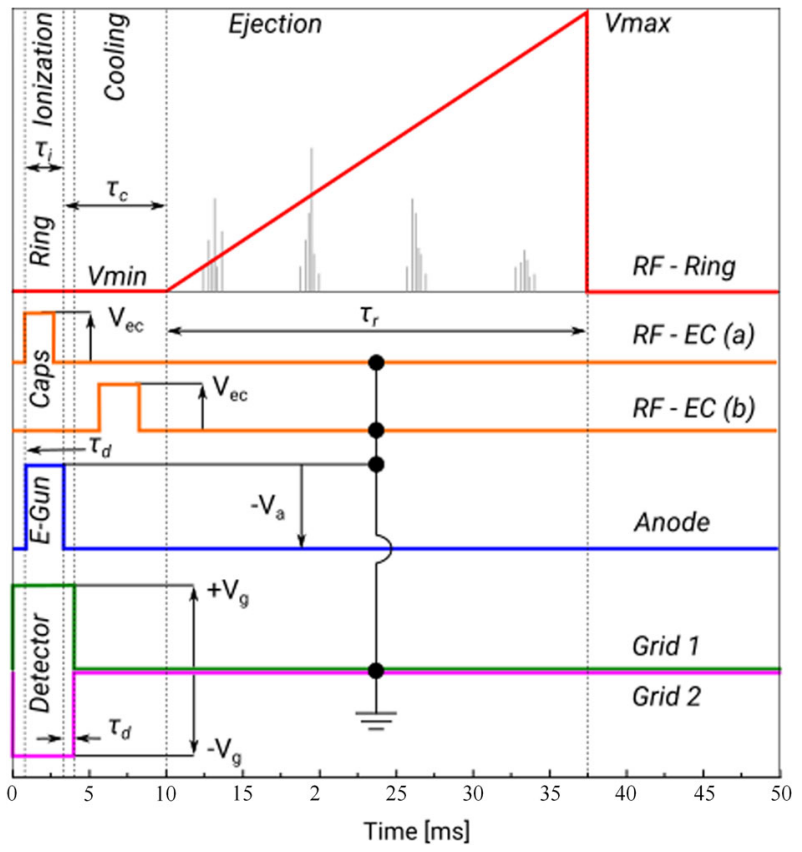

(at least $\Delta m=1$ at the end of the mass range). This is not the case with the JPL QITMS, which rather depends on a very low background pressure $\left(\approx 2 \times 10^{-10} \mathrm{mbar}\right)$, achieved with careful selection of low out-gassing materials and a low weight ion/getter pumping combination; a narrow (1 mm wide) and parallel electron beam for ion creation; and short (0.5-1 ms) ionization intervals; which all results in ion clouds of lesser densities, generated in a narrow cylinder along $\mathrm{z}$-axis of the trap, with negligible ion-to-ion Coulomb interaction Nikolić et al. (2015).

After that, in the ejection phase ( $\left.1 \mathrm{~ms}<\tau_{r}<100 \mathrm{~ms}\right)$, the RF amplitude is increased in linear fashion to some higher value (typically $1000-2000 \mathrm{~V}$ at $1 \mathrm{MHz}$ for the highest ejected $\mathrm{m} / \mathrm{q}$ value of 100-215), which leads to the ejection of ions by mass-selective axial instability, as described by the Mathieu equation, $V_{e}=\left(0.908 r_{0}^{2} \omega^{2} / \mathrm{e}_{0}\right) \times m / q$ March (1997). Here $V_{e}$ represents the amplitude of the RF voltage, $r_{0}$ the inner radius of the trap, $\omega$ the radial frequency of the RF voltage $2 \pi \nu$, and $\mathrm{e}_{0}$ the elemental charge. During this process, ion trajectories are stretched along the $\mathrm{z}$-axis until their amplitudes are large enough for ions to exit through the holes in the end-caps (EC). Lighter species are ejected first, followed by heavier ones, according to their increasing mass/charge (m/q) ratio, with $\sim 70 \%$ efficiency Nikolić et al. (2015). One-half of the ejected ions are lost through the TC hole, the other half travels through the $\mathrm{BC}$ hole and produces small charge pulses upon hitting the detector. These signals are then amplified, shaped into $5 \mathrm{~V}$ transistor logic level pulses, using Amptek A121 pre-amplifier, and binned into corresponding channels, according to the time of their arrival, which is proportional to the amplitude of the RF and (m/q) value of the ejected ion, thus producing a mass spectrum of ejected species.

Mass resolution of the QITMS depends on many factors: the shape and spacing of the three hyperbolic electrodes (ring and two caps), the shape and intensity of the electron beam, the timing sequences, chosen RF frequency, stability of the RF voltage, and the slope and linearity of the RF ramp. If the two caps are grounded, and all the other parameters are 


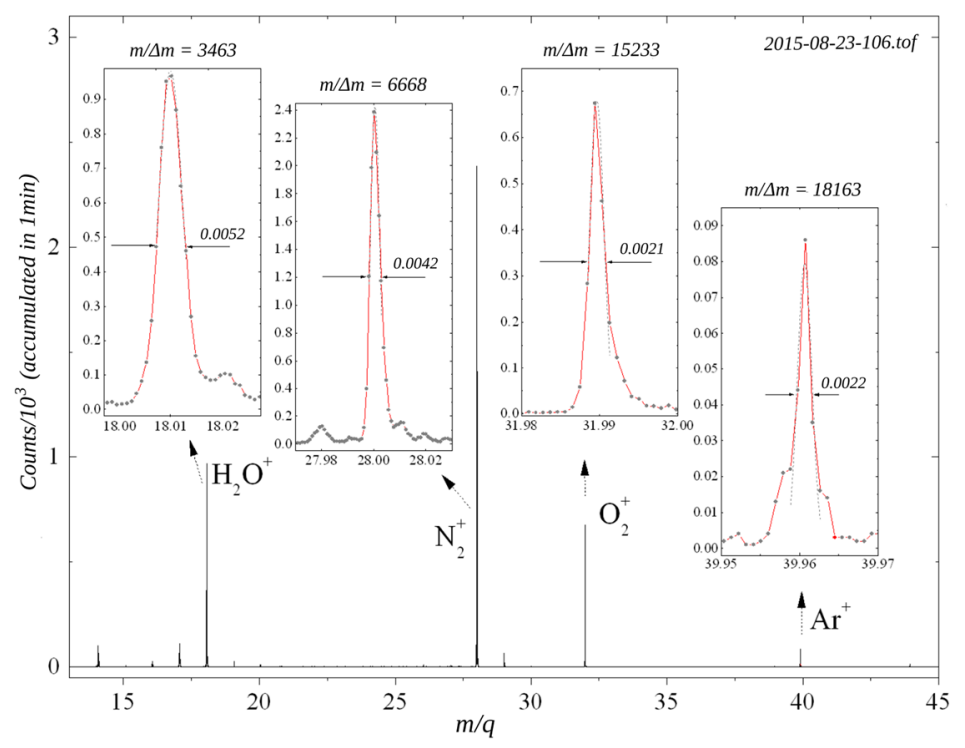

Fig. 3 High mass resolution measurements in the 12-45 m/q interval. Main RF frequency was $1578993 \mathrm{~Hz}$, the ramp was $50 \mathrm{~ms}$ long, linearity of the ramp was constantly monitored and adjusted using a proportional-integral-derivative (PID) control. Dipole excitation frequency was $532750.64 \mathrm{~Hz}$, with the amplitude of $274.0 \mathrm{mV}_{p p}$ (tuned for the $\mathrm{m} / \mathrm{q}=32$ ). The mass resolution, measured at the Full-Width-Half-Maximum (FWHM) of the peaks for different molecules, are listed above their corresponding peaks

carefully adjusted, one can expect to achieve mass resolution of $m / \Delta m$ of $\sim 600$ over the mass range of $600 \mathrm{u}$, and sensitivity of the order of $7.5 \times 10^{12} \mathrm{cnts} / \mathrm{mbar} / \mathrm{sec}$. In case higher mass resolution is needed, one can apply dipole excitation voltage to the top and bottom cap electrodes in addition to the RF voltage already connected to the ring electrode. The two dipole potentials are of the same amplitude, time-synchronized and phase inverted, when one is at its positive peak, the other is at its most negative value. The required amplitude and frequency of the dipole potential are determined empirically, and are usually at a fraction of a volt, and roughly at a third of the main RF voltage resonant frequency. A detailed explanation of the dipole excitation is beyond the scope of this article, in-depth analysis can be found in March (1997), Nikolić et al. (2015). It is worth noting that high mass resolution based on a dipole excitation is achieved at the expense of reduced sensitivity (factor of 1050). Examples of high-resolution measurements with JPL's QITMS are shown in Fig. 3.

\section{Inlet System}

The gas flow to be admitted into the MS depends on the instrument's pumping speed, ambient pressure and the desired operating pressure. In the case of JPL's QITMS, the maximum operating pressure, which still allows for mass resolution of 600 at $\mathrm{m} / \mathrm{q}=600$ and dynamic range of $\sim 10^{5}$, is around $5 \times 10^{-8}$ mbar, although measurements with slightly lower mass resolution and sensitivity can still be performed in high $10^{-5}$ mbar region. We use a combination of ion and getter pumps yielding pumping speeds of approximately $40 \mathrm{l} / \mathrm{s}$, which sets the ideal inlet gas flow at below $2 \times 10^{-6} \mathrm{mbar} 1 / \mathrm{s}$. A proper inlet system should be designed in such a way to restrict the flow of incoming gas below this value. When it comes to atmospheric descent, where outside pressure increases rapidly, an inlet with fixed conductance 
Fig. 4 Closed (top) and opened (bottom) piezoelectric microvalve. Active zones of actuator expand when voltage is applied

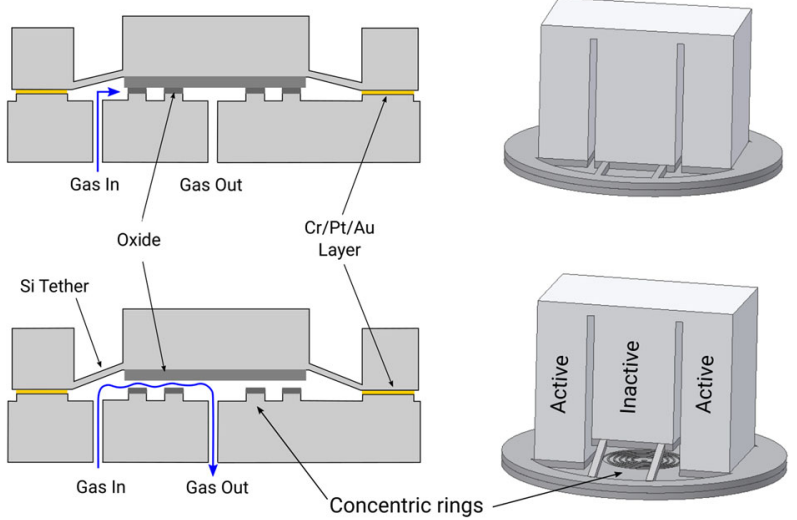

will satisfy flow conditions only in a specific range of altitudes. The solution lies in using a flow restrictor with a variable conductance, which is chemically inert, does not distort the gas composition being sampled by adsorbing or reacting with sampled gases differentially, and has a reasonably fast response time (on the order of tens of milliseconds or less). Finally, such a device must be simple, robust and operable over a wide temperature range. Past methods, of producing such inlet systems, have included pulled glass Niemann et al. (1992), crimped metal tubes Hoffman et al. (1979a,b), porous frits, micro-machined leaks Jamieson et al. (2007), NASA Tech Briefs (2016), and pulsed piezoelectric valves Grechnev et al. (1979), Istomin et al. (1979). So far, none of these methods have produced an inlet system that would satisfy all the conditions mentioned above and would be able to finely regulate sample mass-flow continuously in a wide pressure interval. In Table 1, we summarize methods and types of sample inlet systems that were used in the past flight missions or are being developed at the moment for future explorations. So far, only Pioneer and Venera probes had means of continually variable conductance, not just switching between different leaks. The problems that arose with different types of inlet systems are described in the comment column of Table 1 .

We recently adopted a device based on a piezoelectric (PE) actuator, developed at JPL 16 years ago for high-pressure gas micro-propulsion applications Yang et al. (2004), Lee et al. (2006), Yang et al. (2007) for a novel inlet system, that satisfies all the above requirements. The valve allows for a continually variable conductance of the inlet system, keeping the pressure inside MS constant despite the ambient pressure variations. The valve is specifically optimized for proportional flow control of gas propellant, with measured He leak rates of $2.7 \times 10^{-6} \mathrm{mbar}$ 1/s at 65 bar in its "normally closed" position Yang et al. (2004). The device was successfully tested up to a pressure difference of 100 bar and can operate up to $125^{\circ} \mathrm{C}$. It can function either in pulsed $(1 \mathrm{kHz})$ or static mode of operation. The device is fabricated mostly by the micromachining of silicon wafers. The microvalve consists of a custom-designed piezoelectric stack actuator bonded onto silicon valve components: the seat, boss and tether, in a stainless steel housing.

The most important features of the microvalve include silicon narrow edge seating rings and tensile-stressed silicon tethers, which ensure leak-tight operation. The microvalve components do not include any fragile membranes to allow high-pressure operation. Table 2 contains detailed specifications of the piezoelectric stack actuator used (vendor: Noliac A/S, Denmark) with dimensional parameters. The stack actuator exhibits a very high block-force $(\sim 1 \mathrm{kN})$, and is thus capable of generating a valve-opening pressure far greater than the 
Table 1 Overview of different inlet types used for past flight missions. The only two that allowed for continuous regulation of the mass flow were Pioneer and Venera. Column 1: $\left(\mathrm{p}_{a}\right)$ stands for ambient pressure, $\left(\mathrm{t}_{d}\right)$ for descent time, and (alt) for the altitude. Column 2: Configuration category details how many inlet channels with different fixed conductances were used, and $\mathrm{p}_{\max }$ represents the pressure in the MS at highest ambient pressure

\begin{tabular}{|c|c|c|}
\hline Mission & Inlet type & Comment \\
\hline $\begin{array}{l}\text { Galileo (Jupiter) } \\
\mathrm{p}_{a}: 0.15-20 \text { bar } \\
\mathrm{t}_{d} \sim 60 \text { min }\end{array}$ & $\begin{array}{l}\text { Fixed: }{ }^{a} \text { Leak }+ \text { Valve } \\
\text { Configuration: array of } 4 \\
\mathrm{p}_{\max }=10^{-4} \text { mbar }\end{array}$ & $\begin{array}{l}\text { Difficult to manufacture, prone to single } \\
\text { point failure, characteristics of the leaks } \\
\text { vary, complex, no continuous regulation of } \\
\text { mass flow. Niemann et al. (1992) }\end{array}$ \\
\hline $\begin{array}{l}\text { Pioneer (Venus) } \\
\mathrm{p}_{a}: 0.1-100 \text { bar } \\
\mathrm{t}_{d} \sim 60 \mathrm{~min}\end{array}$ & $\begin{array}{l}\text { Variable: }{ }^{\mathrm{b}} \text { Leak }+ \text { Valve }+\mathrm{VCV}^{\mathrm{c}} \\
\text { Configuration: array of } 2 \\
\mathrm{p}_{\max }=\mathrm{N} / \mathrm{A}\end{array}$ & $\begin{array}{l}\text { Difficult to produce, crimping method } \\
\text { highly irreproducible. Prone to single point } \\
\text { failure - the clogging by a sulfuric acid } \\
\text { droplet was the reason that instrument } \\
\text { didn't collect meaningful data over a } \\
\text { portion of its descent trajectory Hoffman } \\
\text { et al. (1979b). }\end{array}$ \\
\hline
\end{tabular}

Venera 11/12 (Venus) alt: $23 \mathrm{~km}-2 \mathrm{~km}$
Variable: Piezoelectric valve pulsed mode $\left(\mathrm{t}_{r}<5 \mathrm{~ms}\right)$ Configuration: single $\mathrm{p}_{\max }=\mathrm{N} / \mathrm{A}$

Fixed: ${ }^{\mathrm{d}}$ Leak + Valve Configuration: array of 2 $\mathrm{p}_{\max }=10^{-4}$ mbar

Fixed: ${ }^{\mathrm{e}}$ Leak + Valve Configuration: array of 2 $\mathrm{p}_{\text {max }}=8 \times 10^{-6}$ mbar

Fixed: ${ }^{\mathrm{g}}$ Leak + Valve Configuration: array of 7 $\mathrm{p}_{\max }=5 \times 10^{-5}$ mbar
Significant valve dead volume - resulted in pressure bursts which required minutes to stabilize, poor temporal resolution Grechnev et al. (1979), Istomin et al. (1979). Continuous regulation of mass flow achieved through the pulse width regulation.

Difficult to manufacture, prone to single point failure, characteristics of the leaks vary, complex, no continuous regulation of mass flow Niemann et al. (2002).

Difficult to manufacture, prone to single point failure, characteristics of the leaks vary, complex, no continuous regulation of mass flow Hoffman (2010).

MEMS technology, batch manufacturing, no continuous regulation of mass flow, macroscopic solenoid valves (bulky, expensive, 14 bar max pressure difference) Jamieson et al. (2007), NASA Tech Briefs (2016).

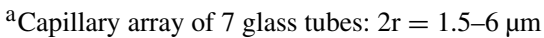

${ }^{\mathrm{b}}$ Crimped Tantalum tubing $2 \mathrm{r}=1 / 8^{\prime \prime}$

${ }^{\mathrm{c}}$ Variable Conductance Valve - continuous mass flow regulation via adjustable pumping speed Hoffman et al. (1979a)

${ }^{\mathrm{d}}$ Capillary array of 7 glass tubes: $2 \mathrm{r}=2-20 \mu \mathrm{m}$

${ }^{\mathrm{e}}$ Capillary array of 7 glass tubes: $2 \mathrm{r}<1 \mu \mathrm{m}$

${ }^{\mathrm{f}}$ In development for flight

${ }^{g}$ Rectangular channels $\left(1.5 \times 1 \mu^{2}\right)$ of various lengths etched into silicone chip, Mindrum valves
} 
Table 2 Properties of the actuator

a Slot: $0.3 \mathrm{~mm}(\mathrm{w}), 5.5 \mathrm{~mm}(\mathrm{~d})$, separating the inactive center from the two active zones

\begin{tabular}{ll}
\hline Properties & Specifications \\
\hline Piezoelectric material & Soft doped PZT $-\mathrm{S} 2$ \\
Dimension - Cross sect. & $8.4 \mathrm{~mm} \times 5 \mathrm{~mm}$ (ceramic) \\
Dimension - Height & $6 \mathrm{~mm}$ \\
Special features & Two slots ${ }^{\mathrm{a}}$ \\
Max. voltage & $+60 \mathrm{~V}$ \\
Max. displacement & $-1 \mu \mathrm{m}(-10 \mathrm{~V}), 5 \mu \mathrm{m}(+60 \mathrm{~V})$ \\
Blocking force & $1000 \mathrm{~N}$ \\
Capacitance & $1700 \mathrm{nF}$ \\
Curie temp. & $235^{\circ} \mathrm{C}$ \\
Max. operating temp. & $125^{\circ} \mathrm{C}$
\end{tabular}

seating pressure made up of the combined inlet gas pressure and the initial seating pressure arising from the tensile-stressed silicon tether suspension. The custom-designed stack of piezoelectric actuators consists of peripheral active zones and an inactive central zone. The active zones are mechanically separated (by deep U-grooves) from the central, inactive zone. These zones are bonded to corresponding peripheral and central areas of the boss plate. Application of a voltage $(\sim 60 \mathrm{~V})$ to the piezoelectric stack causes the active zones to vertically expand by $5 \mu \mathrm{m}$, lifting the boss center plate (bonded to the inactive zone), away from the seat plate. This actuation creates a channel between the two seating surfaces, permitting the passage of gas as shown in Fig. 4.

The piezoelectric actuator is essentially a stacked capacitor, which consumes almost no power when it is not moving, thus allowing a near zero-power operation when the valve is in a fixed position. In pulsed mode, the actuator requires $4 \mathrm{~mJ}$ to fully charge $(\mathrm{RC}=1.7 \mu \mathrm{s})$, thus consuming $8 \mathrm{~W}$ of power if operated between fully open - fully closed states at $1 \mathrm{kHz}$ continuously.

A concentric series of narrow rings on the seat plate (10 rings total) is designed to provide the redundancy necessary to maintain a leak-tight operation in the event of damage to individual seating rings. The narrow rings $(1.5 \mu \mathrm{m}$ wide and $5 \mu \mathrm{m}$ deep simulate a "knife-edge" seal by reducing the contact area, thereby increasing the seating pressure and consequently reducing internal leaks.

The center portion of the boss plate has a $2 \mu \mathrm{m}$ thick silicon dioxide layer functioning as a hard seat coating material. The boss plate is bonded to the seat plate via metal-to-metal compression along the periphery. The thickness of the silicon dioxide coating on the boss plate varies, being slightly thicker $(2.0 \mu \mathrm{m})$ in the center than at the periphery $(1.9 \mu \mathrm{m})$. This oxide thickness difference results in the generation of tensile stress in the silicon tether suspension, which provides an initial valve-seating pressure, as shown in Fig. 4 (Top). The estimated maximum tensile-stresses in the tethers, obtained from an ANSYS simulation Yang et al. (2007), are approximately $80 \mathrm{MPa}$ and $16 \mathrm{MPa}$ during the on-state and the off-state, respectively. These are far lower than the fracture stress of silicon $(\sim 7 \mathrm{GPa})$, thus enabling reliable long-term on-off actuation. The estimated seating pressure from the tethers on the seating rings is approximately $88 \mathrm{kPa}$ for the normally closed operation. The dominant seating pressure, applied by the piezoelectric actuator during the closed-state of the microvalve, is achieved using the following fabrication and assembly procedure: A voltage of $10 \mathrm{~V}$ is applied initially to the piezoelectric stack actuator during bonding onto the boss plate. Once bonded, this assembly procedure ensures that the boss plate is pressed onto the seat plate by the inactive zone (attached to the boss center plate) of the piezoelectric stack prior to the 
Fig. 5 Top view of the microvalve in custom housing with conflate $(\mathrm{CF})$ gasket. Voltage to the actuator is applied through welded electrical feedthroughs
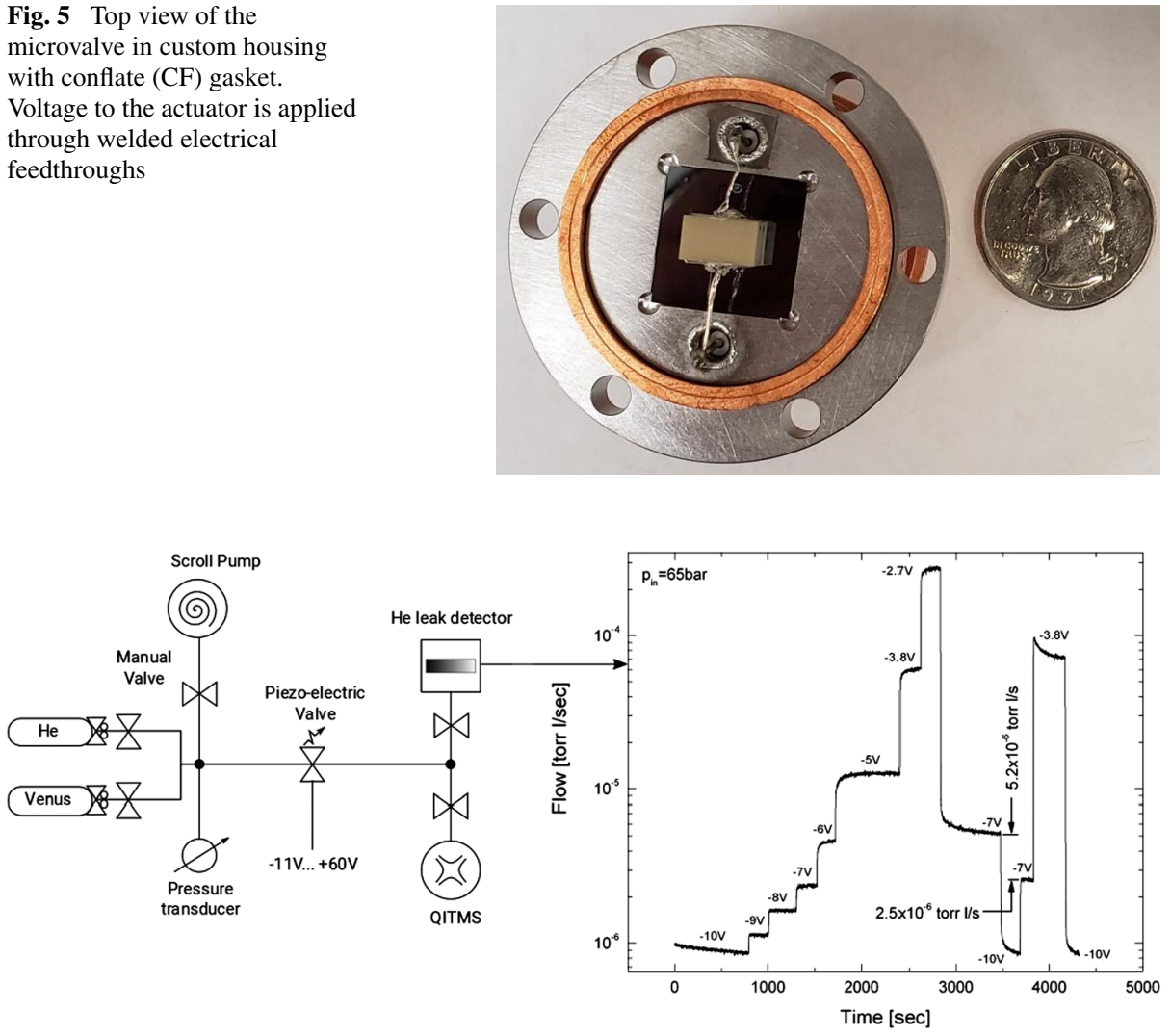

Fig. 6 Left: testing setup for microvalve evaluation. Gas flows at different inlet pressures were measured with He leak detector, mass spectra were obtained by directing Venus gas mixture into the QITMS. Right: Microvalve voltage-flow characteristic curve for the inlet pressure of 65 bar. Hysteresis effect of $\sim 1.5 \mathrm{~V}$ discovered when stepping the voltage down after the initial ramp-up

microvalve operation. Our estimate of this initial valve-closing pressure is approximately $954 \mathrm{MPa}$ Yang et al. (2007) and far exceeds the other sources, described above, for the seating pressure.

A custom leak-tight housing with a pair of electric feedthroughs for actuator activation and Valco gas ports for $1 / 16^{\prime \prime}$ tubing machined into the body of the housing was developed to accomodate the valve and to interface it with the macro world (Fig. 5). Testing of the microvalves in the static mode of operation (a constant voltage applied to the actuator instead of pulses) was performed on the setup depicted in Fig. 6 (left). The valve's characteristics were measured using a pressurized He bottle, where a two-stage regulator was used to establish the inlet pressure, additionally monitored by a transducer sensor. Inlet pressures were gradually increased from ambient to 100 bar in steps of 1, 2, and 5 bar. For each discrete pressure value, the voltage on the microvalve was ramped from $-10 \mathrm{~V}$ (fully closed valve) up to the highest value that still allowed for non-saturated measurement with He leak detector (less than $1.3 \times 10^{-3} \mathrm{mbar} 1 / \mathrm{s}$ ). One of such voltage-flow characteristic curves is shown in Fig. 6 (right). A hysteresis effect, not uncommon for such a piezoelectric type of actuator, was observed while stepping down the voltage after the initial ramp-up. The effect 


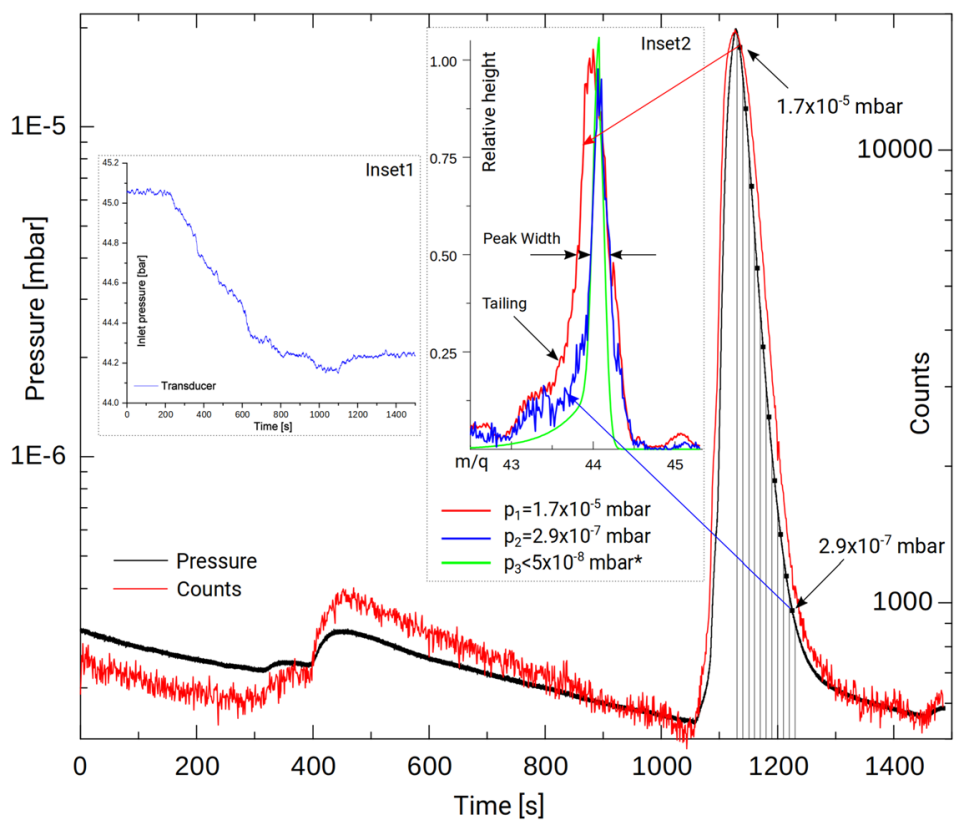

Fig. 7 Testing of QITMS in high pressure conditions, inlet pressure at $\sim 45$ bar (inset $1-$ blue curve), the pressure inside the QITMS varied between $1.0 \times 10^{-7}-2.0 \times 10^{-5} \mathrm{mbar}$, using piezoelectric microvalve. Red curve shows the number of counts from QITMS (right vertical scale), black curve the pressure inside the QITMS (left vertical scale). Inset 2 shows the shape of the $\mathrm{m} / \mathrm{q}=44$ peaks at $1.7 \times 10^{-5} \mathrm{mbar}$ (red), and $2.9 \times 10^{-5}$ mbar (blue), compared to a synthetic mass peak at below $5 \times 10^{-8}$ mbar (green)

was predictable and reproducible with very little variability $( \pm 0.25 \mathrm{~V})$ and did not affect the functionality of the valve.

In the next step, we directed the gas flow from the microvalve to the QITMS and repeated the exercise using Venus atmosphere-like mixture, containing mostly $\mathrm{CO}_{2}(\sim 96 \%)$, $\mathrm{N}_{2}(\sim 3 \%)$, and $\mathrm{O}_{2}$ with other trace species $(\sim 1 \%)$. Figure 7 shows an example of such measurements, where inlet pressure was set to $\sim 45$ bar, while the pressure inside the QITMS was varied from $1.0 \times 10^{-7}$ mbar to $2.0 \times 10^{-5}$ mbar to test the response of the QITMS at high internal operating pressures. During the measurement, we produced a pressure pulse by applying a $1.5 \mathrm{~V}$ voltage increase to the piezoelectric valve for the duration of $0.1 \mathrm{~s}$. We then monitored the performance of the QITMS from the time the pressure inside reached its maximum value, and until it dropped back to the $10^{-7}$ mbar region. Analysis of 10second intervals, marked with black dots on the graph, showed significant peak width and low mass-side tailing increase at a higher pressure for $\mathrm{m} / \mathrm{q}=44$ (Inset 2), a sign of an over-pressurized QITMS. Subsequent measurements with the same inlet and lower QITMS pressures showed that the best results were obtained when the pressure inside the sensor was below $5 \times 10^{-8}$ mbar.

The amount of recorded data $(\mathrm{R})$ of a triggered data acquisition system depends on the rate of pulses delivered (D) to the system and on time it takes to process one event $(\tau)$, also called dead time. In the case of non-paralyzable Leo (1994) detectors and electronics, where pulses arriving during processing interval don't cause a pile-up effect within the device, the ratio between the number of delivered and recorded events can be calculated for random time distributions of the events for a given dead time $\tau$ as: $R=D /(1+D * \tau)$ Leo (1994). When 


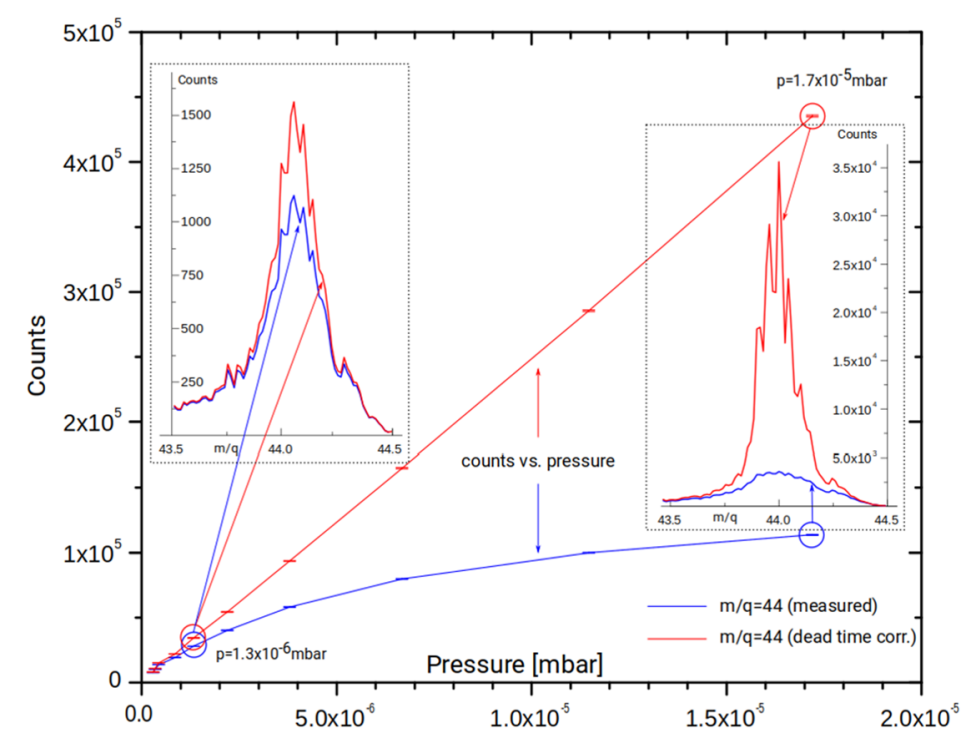

Fig. 8 Dead time corrections of QITMS measurements in high pressure conditions. Number of counts for mass peak $\mathrm{m} / \mathrm{q}=44$, integrated over $10 \mathrm{~s}$ intervals, with increasing pressure. Measured counts (blue curve), dead time corrected counts (red curve). Insets show measured vs corrected $\mathrm{m} / \mathrm{q}=44$ peak heights at $1.3 \times 10^{-6}$ mbar (left) and at $1.7 \times 10^{-5}$ mbar (right)

operating QITMS at high pressures, especially in the presence of dominant species where corresponding pulses are delivered over short periods of time, dead time corrections must be applied to obtain proper peak ratios. The dead time of the QITMS pre-amplifier (Amptek 121 ) is $\sim 100 \mathrm{~ns}$, which in theory allows for $10 \mathrm{MHz}$ rate measurements, but the effects of a dead time are already visible at rates 10-15 times lower. If the processing electronics is able to handle the incoming rate of pulses, a linear increase of counts with increasing operating pressure is expected. Figure 8 shows such measurement for the mass peak $\mathrm{m} / \mathrm{q}=44$, integrated over a $10 \mathrm{~s}$ interval, at the operating pressures shown in Fig. 7. The dependence is clearly non-linear (blue curve), but proper peak heights can be obtained by applying a $100 \mathrm{~ns}$ dead time correction using a formula described above. Corrected counts respond to pressure increase in a linear fashion (red curve). The ratio of corrected to measured peak heights at two pressure points are shown in the insets.

Tests of the dynamic (pulsed) mode of operation of the microvalve were performed to determine the response time of the valve, reproducibility of the injection pulses and its durability. The valve was repeatedly switched from fully closed to fully open position (by applying $-11 \mathrm{~V}$, followed by $+60 \mathrm{~V}$ ) at different frequencies at ambient pressure while monitoring the pressure inside the vacuum chamber being pumped by $80 \mathrm{l} / \mathrm{s}$ turbomolecular pump. The injection pulses varied in length from 0.5 to $20 \mathrm{~ms}$, and were administered in bursts of 10 with $5 \mathrm{~s}$ interval between each pulse. Figure 9 shows pressure readings inside the vacuum chamber corresponding to 10 pulses of $0.5 \mathrm{~ms}$ width, separated by $5 \mathrm{~s}$ intervals. The response time of the valve was found to be $\sim 1 \mathrm{~ms}$, and the injection pulses differ less than $10 \%$ between different series. Finally, the valve was left in a pulsating mode of operation $(1 \mathrm{kHz})$ for extended periods of time (days) to verify its durability. No performance degradation was observed. 
Fig. 9 Pressure response measured inside the vacuum chamber corresponding to a burst of ten pulses from the microvalve, $0.5 \mathrm{~ms}$ wide, separated by $5 \mathrm{~s}$ intervals

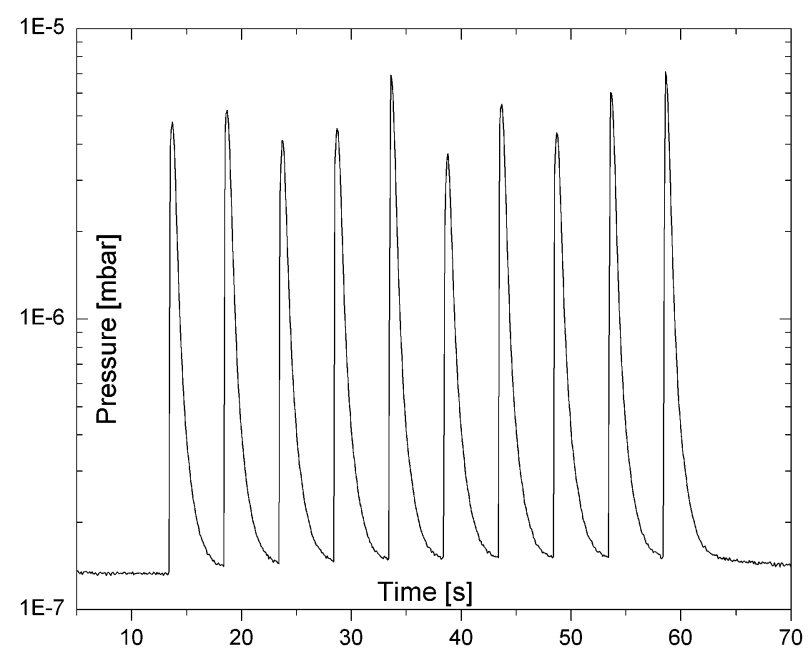

\section{Noble Gas Measurements}

For in-situ exploration of ice giant atmospheres, the measurements of noble gases and noble gas isotopes, are of the highest importance. To demonstrate the ability of the QITMS in combination with the new inlet system for the detection of noble gas abundances, a series of measurements were performed using ambient air. Determining the amounts of noble gases in Earth's atmosphere accurately in a short period of time (1-10 min) presents a challenge, not only because of their low amounts (for example $\mathrm{Kr} \sim 1 \mathrm{ppm}, \mathrm{Xe} \sim 100 \mathrm{ppb}$ ), but also because of the space charge limitations, imposed by the dominant species of argon $(\sim 1 \%)$ and methane, which remain in the gas mixture after the purification of air in the enrichment cell is completed. To achieve the highest possible count rates without causing an extensive broadening of the mass peaks and dead time related distortions of their proportions, the operating pressure inside the QITMS section was adjusted to $\sim 1.5 \times 10^{-6}$ mbar. Figure 10 shows the schematic view of the experimental setup used for the noble gas measurements. The enrichment volume $(\sim 0.8 \mathrm{~L})$ consisted of $2-3 / 4^{\prime \prime}$ cross, connecting tubes and corresponding valves for the getter, ion gauge and turbomolecular pump isolation. Ambient air was administered into the enrichment volume through a microvalve with a single short pulse of a predetermined length to fill the previously evacuated volume with the $8 \times 10^{-4} \mathrm{mbar} \mathrm{L}$ of gas.

All constituents except noble gases and methane were eliminated from the gas mixture in a matter of seconds upon injection, the remaining mixture consisting almost solely of argon $(99 \%)$. Then the manual valve between the two volumes was opened and the noble gas mixture was let into the QITMS volume $(\sim 4.5 \mathrm{~L})$. The setup allowed for ion gauge isolation to eliminate the known effect of ion gauge pumping of noble gases Li and Jousten (2003), which was not exercised during short time measurements described here.

Figure 11 shows an example of air injections performed to calibrate the valve (voltage and pulse duration vs. the amount of injected gas). Series of 3 injections of different duration with different valve conductance were repeatedly administered into the previously evacuated vacuum chamber of known volume with no active pumping (pumps were isolated), and pressure increases were recorded. For example, to achieve the final pressure of $1.5 \times 10^{-6}$ mbar of the purified mixture in the total (QITMS + EV) volume of 5.3 L, the enrichment volume of $0.8 \mathrm{~L}$ had to be filled with $1.0 \times 10^{-3}$ mbar of ambient air. 
Fig. 10 Experimental setup for noble gas measurements. QITMS - left, enrichment volume (EV) right. Ambient air is shown in blue, purified gas mixture in red. TMP stands for a turbomolecular pump, SP for scroll pump, IG for ion gauge, $\mathrm{PV}$ for piezo-electric microvalve, MV for manual valve, and $G_{1}$ and $G_{2}$ for the getter pumps of different sizes. The manual valve separating the purification section from the mass spectrometer volume is shown in red/blue color

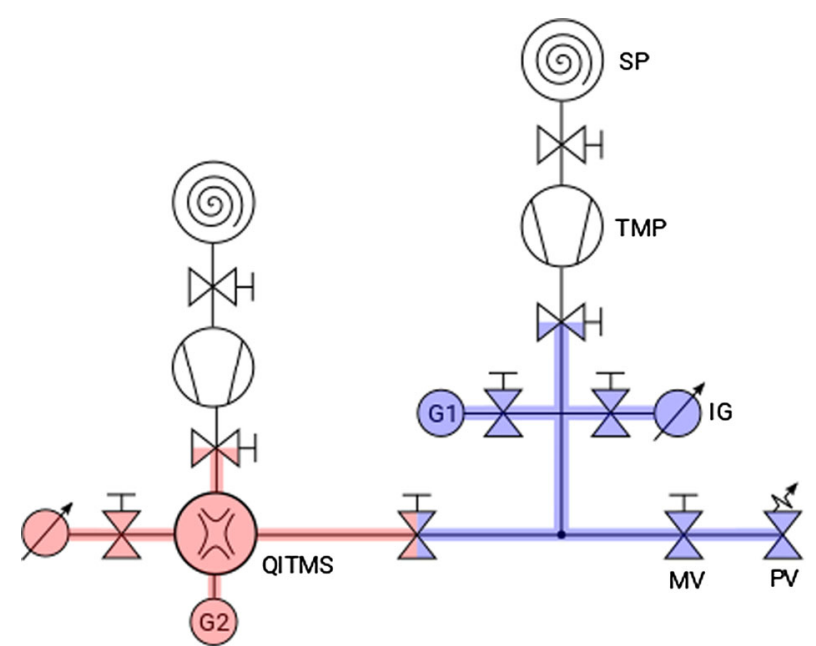

G2)

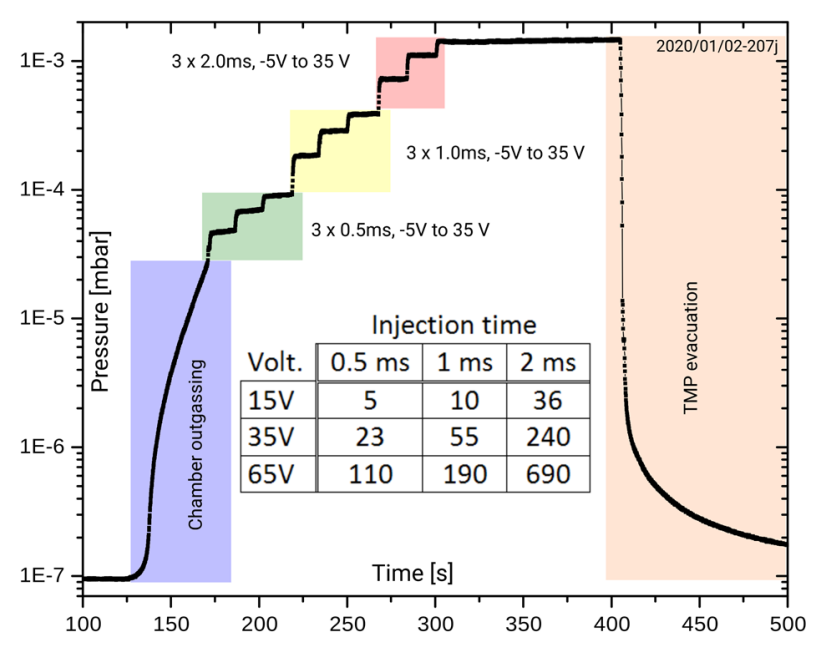

Fig. 11 Microvalve injection calibration. Chamber is first evacuated and isolated from the pump, pressure increases due to outgassing (blue area), series of 3 injections with different duration and valve conductance settings (green, yellow, red), evacuation of the chamber (orange) for another measurement. Inset table shows amounts of gas in $10^{-6}$ mbar L for different injections

Figure 12 shows the mass spectrum of purified gas mixture recorded in 25 minutes over a broad mass range $(\mathrm{m} / \mathrm{q}=17-140)$ at $1.2 \times 10^{-6}$ mbar, obtained with a linear RF ramp, with a low mass cut-off set at $\mathrm{m} / \mathrm{q}=16(110 \mathrm{~V})$, and the RF frequency of $850 \mathrm{kHz}$. To avoid space-charge effects, the filament current was dialed to a very low value of $1.39 \mathrm{~A}$, which resulted in a sensitivity of $1.3 \times 10^{9} \mathrm{cnts} / \mathrm{mbar} / \mathrm{s}$ (typically $1000 \mathrm{X}$ higher). The ionization phase lasted for $20 \mathrm{~ms}$, followed by a ramp of $24 \mathrm{~ms}$, and an ejection phase of $6 \mathrm{~ms}$ to empty the trap of all ions before the beginning of the new cycle. To detect species with $\mathrm{m} / \mathrm{q}$ of 140, the final RF amplitude was, according to the Mathieu equation March (1997), adjusted to 940 V. Despite the low filament setting, the spectrum in Fig. 12 is dominated by saturated and broadened ${ }^{40} \mathrm{Ar}^{+}$peak, spreading over 4 mass units, masking ${ }^{38} \mathrm{Ar}^{+}$isotope almost entirely. $\mathrm{Kr}$ and $\mathrm{Xe}$ are barely visible, to detect those accurately, higher pressure and filament current, and elimination of the argon from the trap are required.

In order to remove Ar ions from the ion trap, the RF ramp was modified by raising the low mass cut-off value to $\mathrm{m} / \mathrm{q}=58$ and by introducing the vertical step at $\mathrm{m} / \mathrm{q}=100$, effectively skipping the area between $\mathrm{Kr}$ and $\mathrm{Xe}(\mathrm{m} / \mathrm{q}=100-120)$ which contained no species. By rais- 


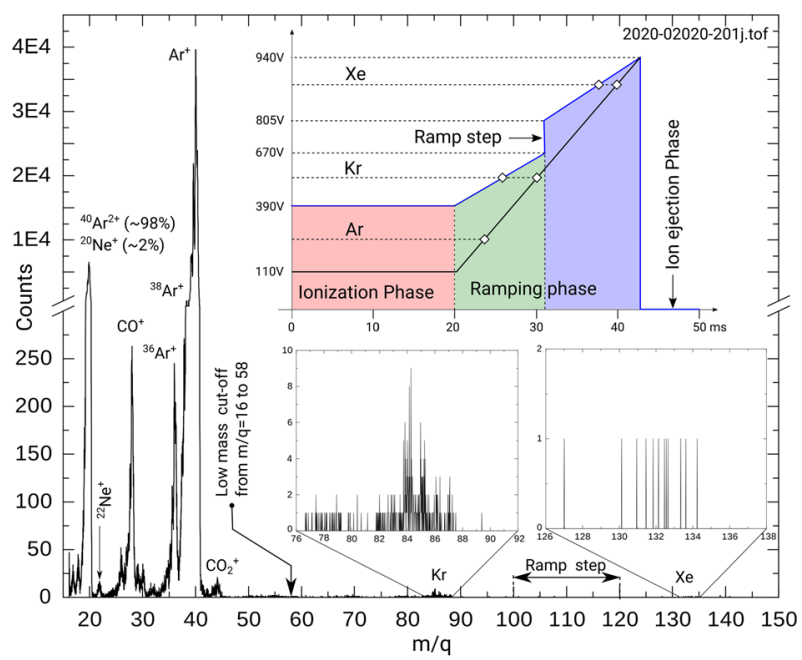

Fig. 12 Mass spectrum of the noble gas mixture over the mass range $\mathrm{m} / \mathrm{q}=16-140$. Besides all three Ar isotopes, we can also see ${ }^{22} \mathrm{Ne}$ and traces of $\mathrm{Kr}$ (bottom-left inset) and $\mathrm{Xe}$ (bottom-right inset). ${ }^{20} \mathrm{Ne}$ is masked by doubly ionized ${ }^{40} \mathrm{Ar}$ peak. Also shown on the $\mathrm{m} / \mathrm{q}$ axis are the positions for the modified ramp low mass cut-off and a ramp step. Top inset shows both ramps, linear with a low mass cut-off at $\mathrm{m} / \mathrm{q}=16$ (black line) and the modified ramp that contains vertical step at $\mathrm{m} / \mathrm{q}=100$, with a low mass cut-off at $\mathrm{m} / \mathrm{q}=58$ (blue line). Horizontal dotted lines with diamond symbols show RF amplitudes, where different species are ejected from the trap

ing the low mass cut-off, argon ions, created in the trap during the ionization phase, were no longer trapped in stable orbits but collided with the trap surface almost instantly after ionization and subsequently neutralized. Consequently, the number of ions in the trap dropped below the space-charge limit, which allowed us to increase the pressure and filament current in the trap, resulting in higher acquisition rates for $\mathrm{Kr}$ and $\mathrm{Xe}$ species. By introducing the vertical step in the ramp, we additionally shortened the ramping interval, which in turn enabled a slower scan across $\mathrm{Kr}$ and $\mathrm{Xe}$ isotopes, thus improving mass resolution over those two regions.

The top inset in Fig. 12 shows the shape of the original (linear) and modified (vertical step) RF ramps. The amplitude of the RF potential during the ionization phase determines the low mass cut-off. In the case of the modified ramp, the RF amplitude of $390 \mathrm{~V}$ was too high for the species below $\mathrm{m} / \mathrm{q}=58$ to be contained in the trap, mass spectrum thus starts at this value and continues up to $\mathrm{m} / \mathrm{q}=140$. The slope of the modified $\mathrm{RF}$ ramp was $515 \mathrm{~V} / 24 \mathrm{~ms}=21.5 \mathrm{~V} / \mathrm{ms}$, compared to $830 \mathrm{~V} / 24 \mathrm{~ms}=34.6 \mathrm{~V} / \mathrm{ms}$ for the linear case. After the ramp modification, the pressure was increased to $2.0 \times 10^{-6} \mathrm{mbar}$, and filament current to $1.56 \mathrm{~A}$, which resulted in a sensitivity of $1.1 \times 10^{12} \mathrm{cnts} / \mathrm{mbar} / \mathrm{s}$. Mass spectra were acquired over 1 and $10 \mathrm{~min}$ intervals to determine how fast these measurements could be performed in a descending probe situation. Results for the $60 \mathrm{~s}$ and $600 \mathrm{~s}$ acquisition times are shown in Figs. 13 and 14, respectively.

Table 3 shows isotope abundances for $\mathrm{Kr}$ and $\mathrm{Xe}$ isotopes obtained with the integration of the counts under the corresponding peak areas and divided with the sum of all counts pertaining to the element. Even with a low number of counts obtained in such a short amount of time, the abundances are surprisingly close to generally accepted experimental (GAE) values Meija et al. (2016). The graphical comparison of measured to GAE values is shown in Fig. 15. 
Fig. 13 Mass spectrum of $\mathrm{Kr}$ and $\mathrm{Xe}$ isotopes acquired in $60 \mathrm{~s}$ time interval. The following isotopes of $\mathrm{Kr}$ clearly showing: $78,80,82,83,84$ and 86 . Visible Xe isotopes are: 129, 131, 132, 134 and 136. Detected contaminants include Acetone $(\mathrm{m} / \mathrm{q}=58)$, benzene $(\mathrm{m} / \mathrm{q}=78)$, and an unknown cluster around $\mathrm{m} / \mathrm{q}=69$, which masks doubly ionized $\mathrm{Xe}$ isotopes

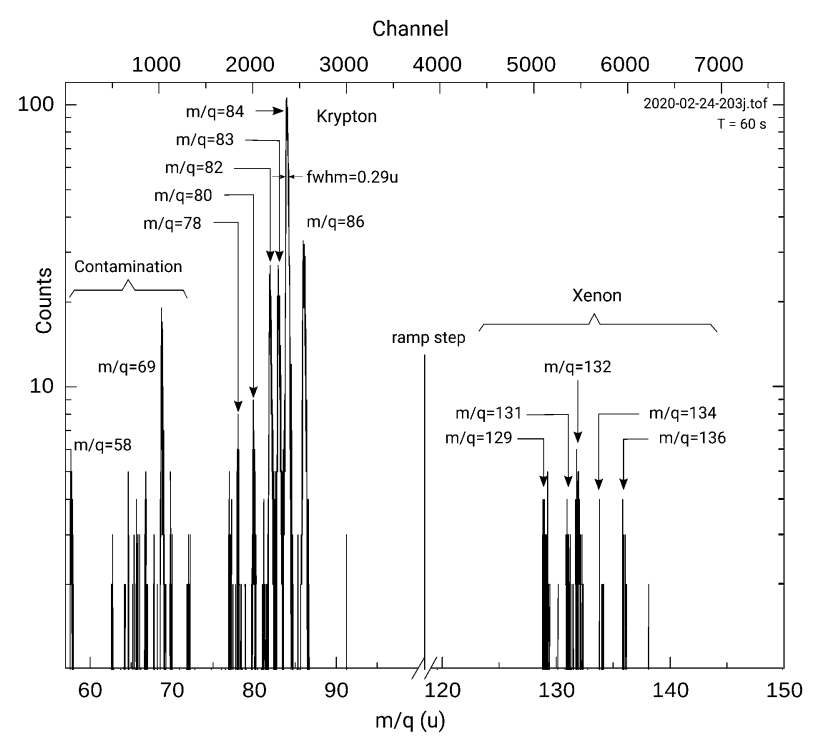

Fig. 14 Mass spectrum of $\mathrm{Kr}$ and $\mathrm{Xe}$ isotopes acquired in $600 \mathrm{~s}$ time interval. The following isotopes of $\mathrm{Kr}$ clearly showing: $78,80,82,83,84$ and 86 . Visible Xe isotopes are: $128,129,130$, 131, 132, 134 and 136. Detected contaminants include Acetone $(\mathrm{m} / \mathrm{q}=58)$, benzene $(\mathrm{m} / \mathrm{q}=78)$, and an unknown cluster around $\mathrm{m} / \mathrm{q}=69$, which masks doubly ionized $\mathrm{Xe}$ isotopes

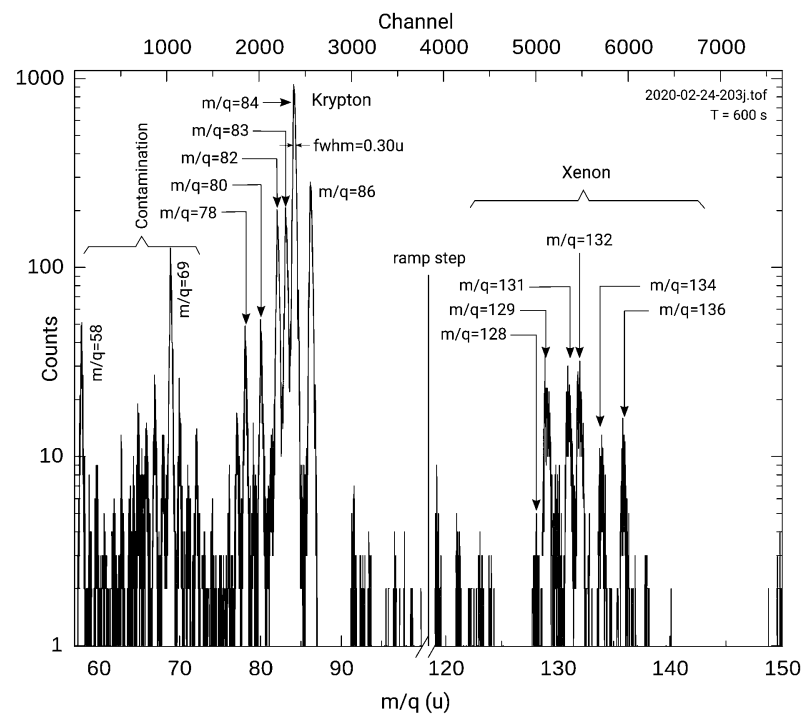

The sensitivity of the instrument while performing these measurements was $\sim 1.1 \times$ $10^{12} \mathrm{cnts} / \mathrm{mbar} / \mathrm{sec}$. Further improvements of the measuring technique (careful alignment of the electron gun, longer ionization interval, higher electron energy) will yield higher values, close to $7.5 \times 10^{12} \mathrm{cnts} / \mathrm{mbar} / \mathrm{sec}$, typically obtained with other JPL QITMS setups Avice et al. (2019).

\section{Resonant Ejection}

The resonant ejection method March (1997) is an alternative to the low mass cut-off ejection method, utilized in the case of noble gas measurements, regularly applied when lower- 
Table 3 Abundances of $\mathrm{Kr}$ and $\mathrm{Xe}$ isotopes measured over a $1 \mathrm{~min}$ (left side of the table) and a $10 \mathrm{~min}$ (right side of the table) intervals. "Cnts" stands for total integrated counts under corresponding isotope peak, "St. Err." column represents statistical error $( \pm \sqrt{C n t s})$, and "Abnd" the percentage of certain isotope in the element. The error in the "Abnd" column is a combined statistical error of the corresponding isotope counts and the sum of the counts for the element. "GAE" column shows generally accepted experimental values for isotope abundances of $\mathrm{Kr}$ and $\mathrm{Xe}$ isotopes in the air Meija et al. (2016)

\begin{tabular}{|c|c|c|c|c|c|c|c|c|}
\hline & \multirow[t]{2}{*}{$\mathrm{m} / \mathrm{q}$} & \multicolumn{3}{|c|}{ Acquisition time $=60 \mathrm{~s}$} & \multicolumn{3}{|c|}{ Acquisition time $=600 \mathrm{~s}$} & \multirow[t]{2}{*}{ GAE $\%$} \\
\hline & & Cnts & St. Err \pm & Abnd $\%$ & Cnts & St. Err \pm & Abnd $\%$ & \\
\hline \multirow[t]{7}{*}{$\mathrm{Kr}$} & 78 & 140 & 11.8 & $2.0 \pm \mathbf{0 . 2}$ & 1523 & 39.0 & $2.3 \pm \mathbf{0 . 1}$ & 0.3552 \\
\hline & 80 & 186 & 13.6 & $2.7 \pm 0.2$ & 1738 & 41.7 & $2.7 \pm \mathbf{0 . 1}$ & 2.2856 \\
\hline & 82 & 796 & 28.2 & $11.6 \pm 0.5$ & 7048 & 84.0 & $10.8 \pm 0.2$ & 11.5930 \\
\hline & 83 & 824 & 28.7 & $12.0 \pm 0.6$ & 7620 & 87.3 & $11.7 \pm 0.2$ & 11.4996 \\
\hline & 84 & 3817 & 61.8 & $55.4 \pm 1.6$ & 36515 & 191.1 & $\mathbf{5 5 . 8} \pm \mathbf{0 . 5}$ & 56.9877 \\
\hline & 86 & 1127 & 33.6 & $\mathbf{1 6 . 4} \pm \mathbf{0 . 7}$ & 10960 & 104.7 & $16.8 \pm \mathbf{0 . 2}$ & 17.2790 \\
\hline & Total & 6890 & 83.0 & & 65404 & 255.7 & & \\
\hline \multirow[t]{8}{*}{$\mathrm{Xe}$} & 128 & 6 & 2.4 & $1.3 \pm 0.6$ & 102 & 10.1 & $2.1 \pm 0.2$ & 1.9102 \\
\hline & 129 & 109 & 10.4 & $23.1 \pm 3.3$ & 1224 & 35.0 & $25.2 \pm 1.1$ & 26.4006 \\
\hline & 130 & 26 & 5.1 & $5.5 \pm 1.3$ & 256 & 16.0 & $5.3 \pm 0.4$ & 4.0710 \\
\hline & 131 & 103 & 10.1 & $21.9 \pm 3.2$ & 1108 & 33.3 & $22.8 \pm 1.0$ & 21.2324 \\
\hline & 132 & 133 & 11.5 & $28.2 \pm 3.7$ & 1243 & 35.3 & $25.6 \pm 1.1$ & 26.9086 \\
\hline & 134 & 41 & 6.4 & $8.7 \pm 1.8$ & 456 & 21.4 & $9.4 \pm \mathbf{0 . 6}$ & 10.4357 \\
\hline & 136 & 53 & 7.3 & $11.3 \pm 2.1$ & 467 & 21.6 & $9.6 \pm 0.6$ & 8.8573 \\
\hline & Total & 471 & 21.7 & & 4856 & 69.7 & & \\
\hline
\end{tabular}
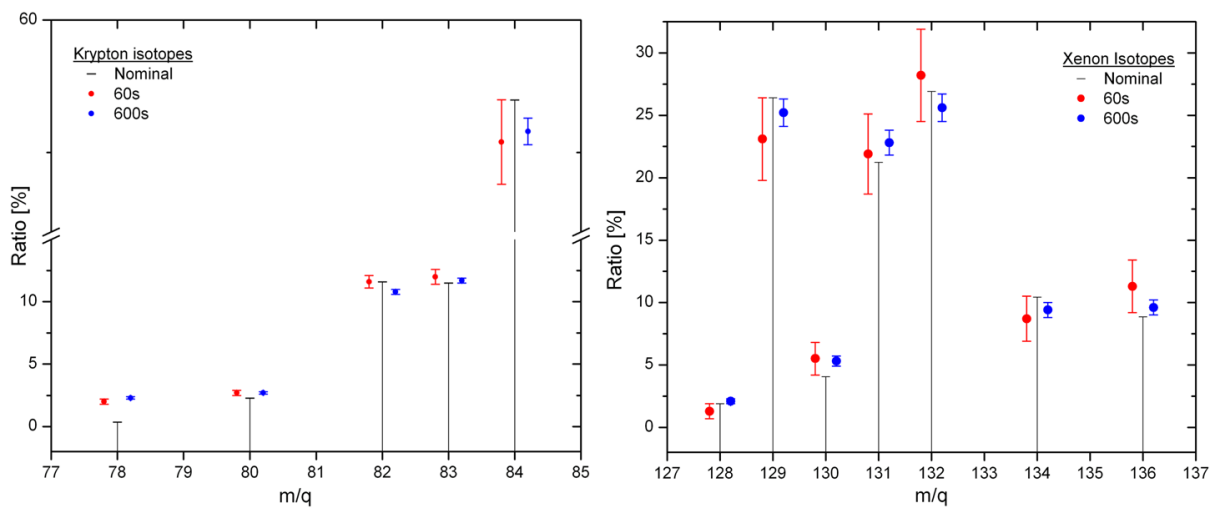

Fig. 15 Comparison of measured abundances of $\mathrm{Kr}$ and $\mathrm{Xe}$ isotopes to generally accepted experimental (GAE) values. Krypton isotopes on the left, Xenon on the right. Red symbols represent results of $60 \mathrm{~s}$ long measurement, blue the ones obtained over $600 \mathrm{~s}$ of measurement. GAE values are black. Discrepancy at mass 78 is probably due to contamination with trace amounts of benzene

ing the numbers of dominant ion species in the trap is required to detect trace amounts of other species. While the low mass cut-off method can only be applied during the ionization phase and affects all masses below the cut-off threshold, resonant ejection can target select masses during all three phases of measurement. It is most efficient if triggered during the 

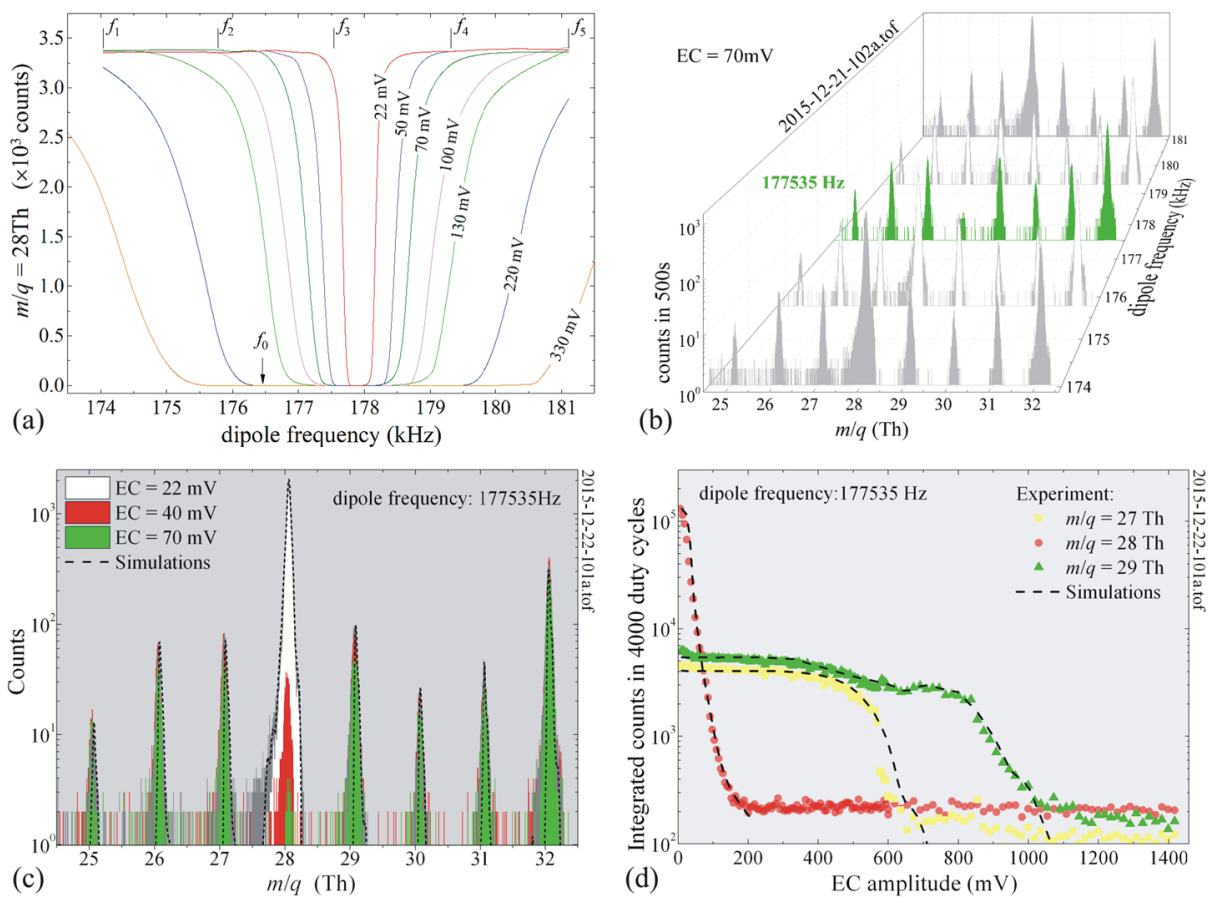

Fig. 16 Simulations of resonant excitation and experimental results. (a) Simulated detection efficiency for $\mathrm{m} / \mathrm{q}=28$ ions under resonant excitation conditions due to dipole potential of variable amplitude $(22-330 \mathrm{mV})$ and frequency $(174-181 \mathrm{kHz})$. The duty cycle is defined by potentials in Fig. 2 such that the amplitude of the ring potential $(207.4 \mathrm{~V})$ has zero variance. (b) Section of the mass spectrum demonstrating the reduction of peak intensities in vicinity of $\mathrm{m} / \mathrm{q}=28$ with the increase of the end-cap frequency. (c) Similar to (b) but for different amplitudes. (d) Reduction in intensity for $\mathrm{m} / \mathrm{q}=27-29$ lines with the increase of end-cap dipole amplitude

ionization phase though, so that majorities of trapped ions from the dominant species are destabilized immediately after their creation and quickly collide with the interior surfaces of either the central ring electrode or one of the two end-cap electrodes. These ions neutralize immediately upon the contact with the metal surface and, since they are no longer confined by applied electrostatic forces, leave the trap. Consequently, they do not contribute to the space charge effects in the central part of the trapping volume, where ions from trace species are created and trapped. Ion motion in the ionization and cooling phase (see Fig. 2) is characterized by radial and axial secular frequencies $\omega_{r, 0}$ and $\omega_{z, 0}$, respectively, and can be destabilized by applying a weak phase-inverted sinusoidal potential difference, of characteristic frequency that matches a particular specie, across the EC electrodes. In the resonant ejection method, we generate such potentials for each targeted specie, sum them up and apply them to the EC electrodes. This is of particular interest since the JPL QITMS is best operated with less than 5000 ions stored in the trap at any given moment to avoid spacecharge effects. Depending on the duration of the ionization and ejection phases in Fig. 2, the detector count rate can be increased up to $5 \times 10^{5}$ ions per second, while operating in this near-ideal mode with negligible ion-ion interaction.

The response of the stored ions in the JPL QITMS sensor to the time-dependent (at $1 \mathrm{~ns}$ resolution) EC potentials (see Fig. 2 - Caps) was first studied using Computational Ion Trap Analyzer (CITA) Nikolić et al. (2015) and is displayed in Fig. 16(a). In this simulation, the 
initial ion cloud was thermalized at $300 \mathrm{~K}$ and contained $3 \times 10^{4}$ singly charged ions randomly assigned to $\mathrm{m} / \mathrm{q}=25-32$ mass lines. Random assignments included creation times within the ionization phase and positions inside $3 \mathrm{~mm}$ long and $1 \mathrm{~mm}$ wide cylinder centered in the middle of the trap and oriented along z-axis. During simulations of the ion trajectories we neglected both the pressure broadening due to rare collisions with neutral molecules and space charge effects due to the weak ion-ion interaction, which is justified in a near-ideal mode of operation (less than 5000 ions in the trap). However, every 130 duty cycles, shown in Fig. 2, we allowed for a random $0.2 \%$ variance in the amplitude of ring potential during both the cooling and the ejection phase. In real-time experiments, these rare changes in the amplitude of ring potential represent the near-resonance characteristics of the non-stabilized voltage mode of the electronics operation and occur mostly due to temperature-induced changes in the resonant coil inductance. Small reductions in the slope of the RF ramp Fig. 2 (top panel) would result in the slight broadening of the high-mass wing of every experimental mass line, and could be corrected for using the MassAlignment tool Madzunkov and Nikolić (2014) post measurement. In the present study of a resonant ejection, we chose to incorporate lowering of the ring potential directly into the simulated mass spectrum to quantify its effects on the measured ion ejection efficiencies by comparing them with simulation results obtained with non-perturbed ring potential. Figure 16(a) illustrates how the simulated resonant ejection efficiency for the $\mathrm{m} / \mathrm{q}=28$ ion fragment changes with the dipole frequency and the dipole amplitude when the ring potential amplitude was held at $207.4 \mathrm{~V}$. The dipole frequency $f_{0}=176.455 \mathrm{kHz}$ was the secular frequency calculated using Eq. (24) of Carrico Carrico (1972). Simulations also revealed the importance of the ring voltage stability. If for a fixed dipole frequency, the ring potential amplitude was lowered by $0.58 \%$ $(1.2 \mathrm{~V})$, all simulated suppression curves in Fig. 16(a) would shift by $\sim 1.07 \mathrm{kHz}$ to lower frequencies, which could (depending on the dipole amplitude value) result in an increased survival probability for targeted ions. For example, the simulated survival probability for the $\mathrm{m} / \mathrm{q}=28$ ions (using a dipole amplitude of $70 \mathrm{mV}$ ) increased from $0 \%$ to $12 \%$ when the ring potential amplitude was lowered by $1.2 \mathrm{~V}$. Simulated detection efficiencies in Fig. 16(a) suggest that it is beneficial to use higher dipole amplitudes if the cooling phase ring potential cannot be stabilized to better than $1 \%$. However, dipole amplitudes should be small enough not to affect nearby mass spectrum lines, as discovered later during experimental measurements and shown in Fig. 16(c,d).

After performing the simulations and obtaining the theoretical value for the dipole frequency, we proceeded with the experimental search for the proper dipole amplitude and frequency for $\mathrm{m} / \mathrm{q}=28$ suppression. The first set of measurements was performed without introducing a gas sample, utilizing a chamber background gas at $2.7 \times 10^{-9}$ mbar instead. Dipole frequencies, applied during the cooling phase (EC(b) case in Fig. 2), between $\mathrm{f}_{1}=174.037 \mathrm{kHz}$ and $\mathrm{f}_{5}=181.104 \mathrm{kHz}$, were used in the experimental frequency search as illustrated in Fig. 16(b). The mass spectrum shaded green in Fig. 16(b) corresponds to the maximum suppression of the $\mathrm{m} / \mathrm{q}=28$ peak using the dipole frequency $\mathrm{f}_{3}$. After identifying the most effective resonant frequency for the ejection of $\mathrm{m} / \mathrm{q}=28$ ions, we used this frequency in a second set of measurements in which we systematically increased the EC dipole amplitude from $22 \mathrm{mV}$ to $1400 \mathrm{mV}$. Results are summarized in Figs. 16(c) and 16(d). Figure 16(c) shows three mass spectra where ions with $\mathrm{m} / \mathrm{q}=28$ were resonantly ejected using EC dipole frequency $f_{3}$ but with varying EC dipole amplitudes. Little to no ejection at $22 \mathrm{mV}$ dipole amplitude was observed. Moderate ejection with a peak reduction by a factor of approximately 100 was observed at $40 \mathrm{mV}$. Very strong ejection was achieved at $70 \mathrm{mV}$ dipole amplitude, reducing the $\mathrm{m} / \mathrm{q}=28$ peak by a factor of almost 1000 . At the same time, peaks at the $\mathrm{m} / \mathrm{q}=27$ and 29 did not experience detectable changes. Figure 16(d) shows the 
Fig. 17 Mass spectrum in the vicinity of $\mathrm{m} / \mathrm{q}=28$ and resonant ejection during the $3 \mathrm{~ms}$ ionization period: (a) linear scale of $\mathrm{m} / \mathrm{q}=10-50$ mass range; (b) logarithmic scale of $\mathrm{m} / \mathrm{q}=16-32$
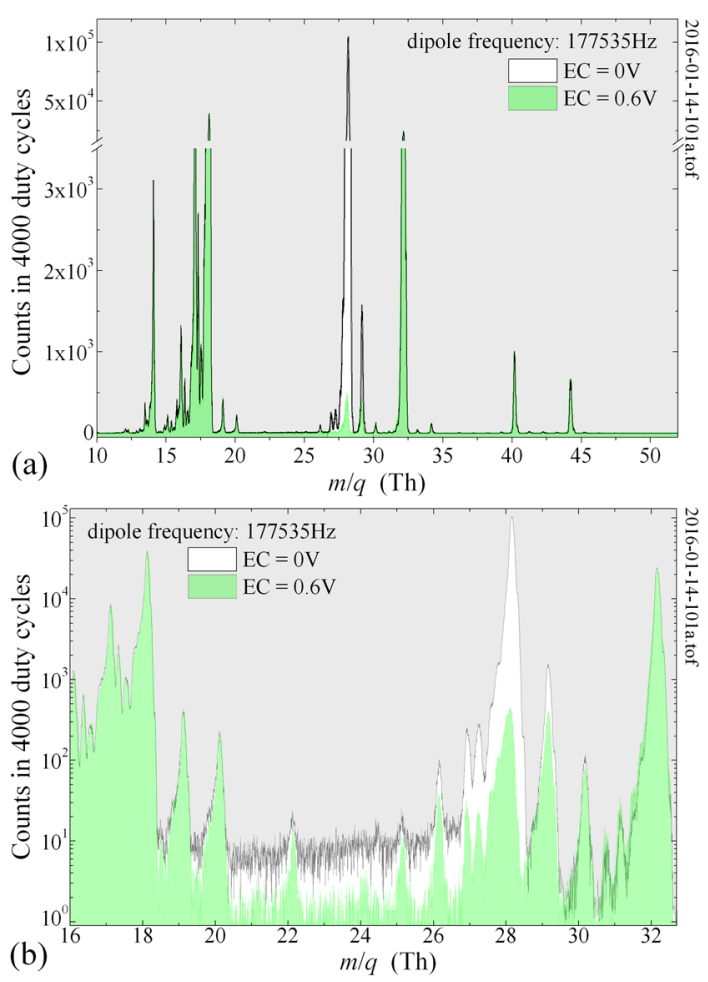

integrated signal under the $\mathrm{m} / \mathrm{q}=27,28$ and 29 peaks for different dipole amplitudes, and with fixed EC dipole frequency $f_{3}$. These observations demonstrate that for amplitudes up to $150 \mathrm{mV}$, the most efficient ejection of $\mathrm{m} / \mathrm{q}=28$ ions were achieved without affecting nearby mass lines. Further increases in dipole amplitude made the field sufficiently strong as to excite neighboring masses. At higher dipole amplitudes, $\mathrm{m} / \mathrm{q}=27$ and 29 peaks also started experiencing resonant excitation. The range of amplitudes for which an effective ejection of $\mathrm{m} / \mathrm{q}=28$ was achieved, but before $\mathrm{m} / \mathrm{q}=27$ and 29 were significantly affected, was relatively wide. To reproduce the observed shoulder feature seen in the suppression of $\mathrm{m} / \mathrm{q}=29$ for dipole amplitudes larger than $650 \mathrm{mV}$, simulations had to allow for the lowering of the ring potential amplitude with a random variance of up to $0.2 \%$. Shown agreement between simulated and experimental results confirmed that simulation tools could be used to predict stable operating conditions for which the JPL QITMS will successfully utilize the resonance ejection technique.

To further demonstrate the usefulness of the technique, we proceeded with the second set of measurements where resonance ejection was applied during the ionization phase (see end-cap(a) panel in Fig. 2). Changes in the mass spectrum of an ambient air sample pumped down to $2.7 \times 10^{-8}$ mbar due to the resonant ejection are illustrated in Fig. 17. The dominant nitrogen peak at $\mathrm{m} / \mathrm{q}=28$ was suppressed by a factor of 3000 , while peaks at $\mathrm{m} / \mathrm{q}=18,32$, 40, 44 remained unaffected. The background levels between water $\mathrm{m} / \mathrm{q}=18$ and nitrogen $\mathrm{m} / \mathrm{q}=28$ peaks were also suppressed, indicating the origin of the peak height reduction is in the low-mass tailing of the dominant $\mathrm{m} / \mathrm{q}=28$ line. Consequently, newly revealed peaks at $\mathrm{m} / \mathrm{q}=22,25$ and 26 could be characterized with better signal-to-noise ratio than before applying the dipole ejection of $\mathrm{m} / \mathrm{q}=28$ nitrogen ions. Results shown so far were obtained 
in the dynamic mode with the ion pump actively maintaining the optimal pressure inside the QITMS sensor.

Experimental conditions and sample purification methods for the third set of resonant ejection measurements were similar to one described in the noble gas measurements section, except for two vacuum chambers of different volumes being used (4.5 L and 0.4 L). The measurements were carried out in static pressure mode Avice et al. (2019), where previously purified gas was introduced into the vacuum chamber containing only a getter element for pumping the out-gassing from the chamber walls. The measurements lasted for several hours. After their completion, the sample gas was evacuated from the vacuum system by two turbopumps, one serving the trap chamber and the other, the purification line. In addition, an RF feedback loop was implemented to enhance the stability of the RF ramp: the high voltage side of RF resonance circuit was capacitively coupled to an analog to digital converter (ADC) and a gain modifier was applied every second, based on the average of the ADC measurements within the past second, compensating for environmental changes in the LC RF amplifying circuit. This feedback loop regulated the high voltage RF waveform reproducible to less than a $0.1 \%$ deviation in amplitude relative to the first ramp. The stability of the RF waveform in every duty cycle was important for locking the ions' secular frequencies.

The sample consisted initially of $99 \% \mathrm{CO}_{2}$ and $1 \%$ of $\mathrm{Ar}, \mathrm{Kr}$, and $\mathrm{Xe}$ mixture with a relative proportion of 50,000:5:1. After scrubbing the $\mathrm{CO}_{2}$ component away in the purification stage, the remaining gas mixture consisted mostly of noble gases, with argon being the dominant specie. The resulting mass spectrum is shown in Fig. 18(a) and is dominated by $\mathrm{Ar}(\mathrm{m} / \mathrm{q}=40)$ from the gas sample. In addition, we observe the appearance of $\mathrm{CH}_{3}$ and $\mathrm{CH}_{4}(\mathrm{~m} / \mathrm{q}=15$ and 16$)$. These molecules are continuously produced by the hot filament. It is evident that $\mathrm{Ar}, \mathrm{CH}_{3}$, and $\mathrm{CH}_{4}$ singly-charged ions are so abundant that the resulting signals are each saturated due to the dead time of the detector pre-amplifier (Amptek A121).

During the course of the measurement the dipole signal was repeatedly turned on and off to demonstrate the effect of resonant ejection during the ionization phase. We used three dipole frequencies to match secular frequencies of $\mathrm{m} / \mathrm{q}=15,16$ and 40 species simultaneously. The mass spectrum with the applied resonant ejection signal is shown in Fig. 18(b). Targeted mass peaks at $\mathrm{m} / \mathrm{q}=15,16$ and 40 are significantly suppressed in the detected ion signal. In addition, we observe increased sensitivity for the rest of the confined ion species. For example, the total Xe count rate detected over time changes from 600 to 900 ions per second when the dipole ejections are activated (Fig. 18(c)). This effect is due to the selective removal of significant portions of most abundant ions in the early stages of their confinement, thus reducing the space-charge effects and preventing the loss of some portions of weakly trapped ions across all masses. In general, measurements of absolute gas concentrations of trace species can be biased by the presence of space charge and are improved by the present technique. For example, the inset in Fig. 18(b) is an enlargement of the Xe isotope region. When compared to the corresponding inset in Fig. 18(a), which is obtained without dipole ejection, mass peaks appear with a greater integrated count rate but with a slightly increased full width at half maximum (FWHM). In this example peak separation is reduced across the spectrum, but mass resolution can be improved in future studies by either activating the additional resonant RF frequency on the end-cap electrodes while in the ejection phase, or by slowing the mass scan rate over the selected range of isotopes as done in Fig. 19. In both cases the use of helium buffer gas March (1997) was not required.

The effect of lowering the filament emission current until the dead time is no longer an issue is illustrated in Fig. 19. The total number of ions created in a single mass scan is reduced. While this enables rapid measurement of abundance ratios for dominant ion species, 

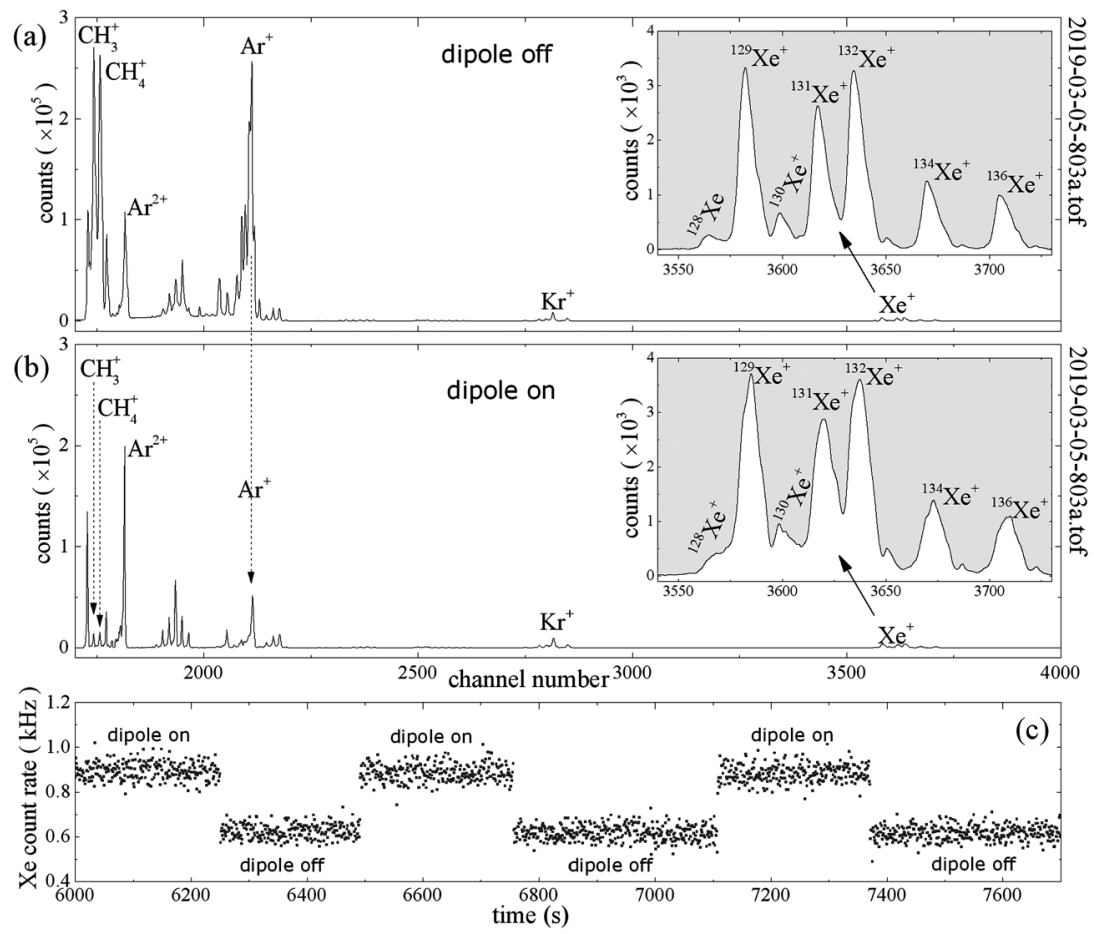

Fig. 18 Experimental results of the measurement of a gas sample in static mode (pumps isolated): (a) mass spectrum obtained without active dipole over a full mass range and Xe isotope range (inset); (b) same as above but with a dipole active during ionization - the dipole waveform is a superposition of $3 \mathrm{RF}$ sine waves where frequencies are selected to match secular frequencies of m/q 15, 16 and 40; (c) total Xe count rate versus time at $1 \mathrm{~s}$ time resolution with dipole ejection periodically being turned on and off. Activation of dipole leads to an $50 \%$ increase of the Xe signal

the reduced count rate for trace ion species implies longer signal accumulation times for reaching satisfactory count statistics. Therefore, the use of higher thermo-electron emissions in combination with the resonant ejection of dominant ion species is an opportunity to preserve good counting statistics on less abundant isotopes.

\section{Summary}

Results obtained in this study demonstrate the capabilities of JPL QITMS, and its inlet system, to perform quick and accurate measurements of major and trace species, including the noble gases and their isotope ratios, during the atmospheric descent. In addition, we present two techniques, low mass cut-off and selective resonance ejection, for effective removal of a significant amount of ions that are unwanted in trace gas mass spectrum analysis. A combination of several dominant species, with different $\mathrm{m} / \mathrm{q}$ values, can be ejected simultaneously by simply raising the trapping potential, or by utilizing a dipole potential that is a linear combination of two or more corresponding secular frequencies. The application of these methods provides three significant improvements for the performance of the ion trap based mass spectrometers, which are of particular importance for atmospheric descent type of measurements. Firstly, the background created by low-mass tailing of dominant peaks is 


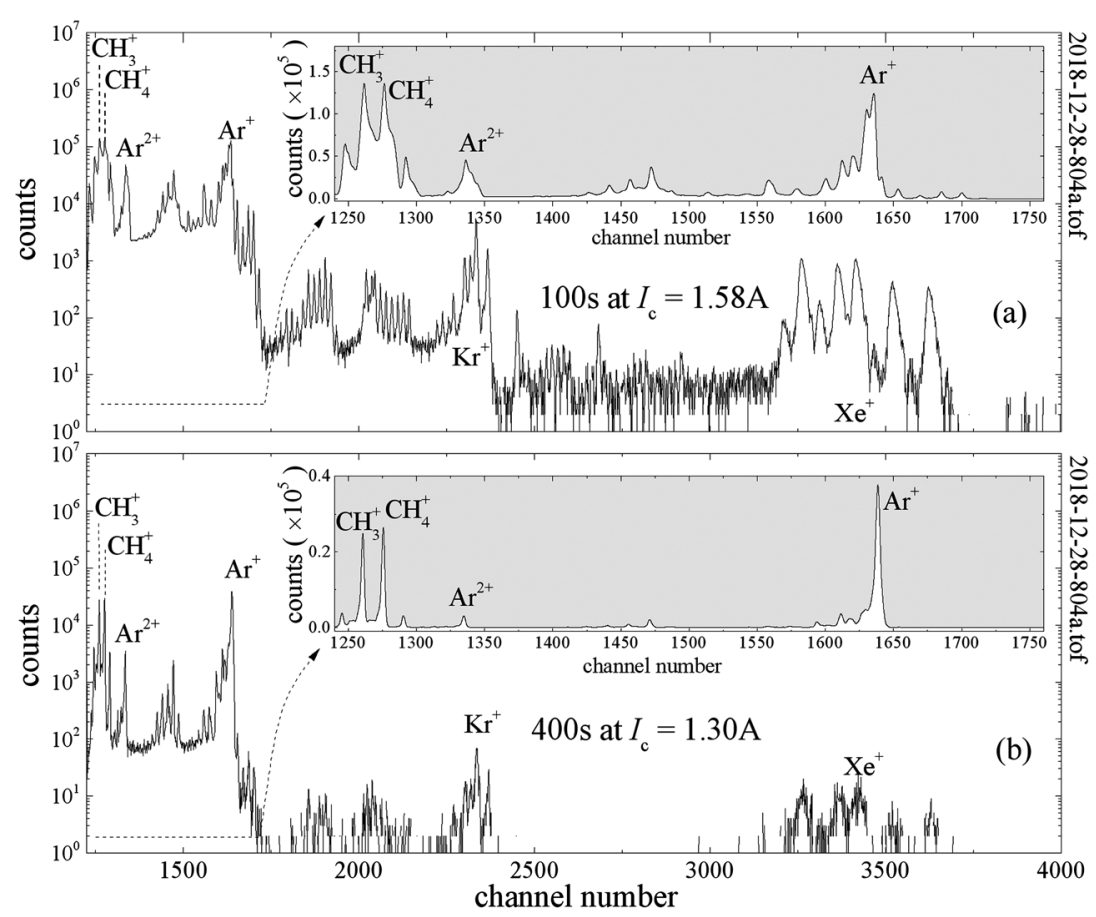

Fig. 19 Mass spectrum in logarithmic scale as recorded in the static pressure mode, without dipole ejection, and at two different thermo-electron emissions from the hot cathode filament. Data was accumulated for (a) $100 \mathrm{~s}$ at high cathode current, $\mathrm{I}_{C}=1.58 \mathrm{~A}$ and (b) $400 \mathrm{~s}$ at low cathode current, $\mathrm{I}_{c}=1.30 \mathrm{~A}$. In both measurements the RF scan function over the Xe isotope range was made three times slower than the rest of the spectrum to increase Xe isotope separation. Insets show with a linear scale the low mass range of the recorded data

reduced and less-prominent mass peaks can be recovered with an improved signal-to-noise ratio. Secondly, the dynamic range of the instrument may be increased by several orders of magnitude. Using higher ionization electron current densities simultaneously with either of these two methods during the ionization phase circumvents the problem of overloading the trap with fragment ions of dominant species to prioritize the selective detection of trace species. Thirdly, we demonstrate on the gas sample analog of Venus' atmosphere, that the sensitivity for the measurements of trace species is increased by about $50 \%$ when the resonant ejection is applied to suppress dominant peaks in a static pressure measurement of noble gases. Applying these methods during atmospheric descent measurements does not limit the ability to calibrate the instrument for absolute atmospheric partial pressures. Depending on the method used, periodically the resonant ejection can be disabled, or trapping potential lowered, for a duration of a single duty cycle. At the same time, the length of the ionization phase can be shortened appropriately such that only dominant species are detected and used for calibration of the absolute partial pressures.

Acknowledgements Many thanks to Dr. Frank Maiwald, and Rani and Ela Simcic for finding some of the missing commas and articles, and putting them where they rightfully belong.

The research was carried out at the Jet Propulsion Laboratory, California Institute of Technology, under a contract with the National Aeronautics and Space Administration. Copyright 2020 all rights reserved. U.S. Government sponsorship acknowledged. 
Publisher's Note Springer Nature remains neutral with regard to jurisdictional claims in published maps and institutional affiliations.

Open Access This article is licensed under a Creative Commons Attribution 4.0 International License, which permits use, sharing, adaptation, distribution and reproduction in any medium or format, as long as you give appropriate credit to the original author(s) and the source, provide a link to the Creative Commons licence, and indicate if changes were made. The images or other third party material in this article are included in the article's Creative Commons licence, unless indicated otherwise in a credit line to the material. If material is not included in the article's Creative Commons licence and your intended use is not permitted by statutory regulation or exceeds the permitted use, you will need to obtain permission directly from the copyright holder. To view a copy of this licence, visit http://creativecommons.org/licenses/by/4.0/.

\section{References}

D.M. Anderson, K. Biemann, L.E. Orgel, J. Oro, T. Owen, G.P. Shulman, P. Toulmin III., H.C. Urey, Mass spectrometric analysis of organic compounds, water and volatile constituents in the atmosphere and surface of Mars: the Viking Mars Lander. Icarus 16(1), 111-138 (1972)

D.H. Atkinson, T.R. Spilker, J. Lunine, A. Simon-Miller, S.K. Atreya, W. Brinckerhoff, A. Colaprete, A. Coustenis, T. Guillot, P. Mahaffy, K. Reh, L. Spilker, A shallow entry probe mission to Saturn, in $E G U$ General Assem. Conf. Abstract, vol. 14 (2012), p. 3172

D.H. Atkinson, A. Coustenis, J. Lunine, A. Simon-Miller, S.K. Atreya, W. Brinckerhoff, A. Colaprete, A. Coustenis, T. Guillot, P. Mahaffy, K. Reh, L. Spilker, T.R. Spilker, C. Webster, Science from Saturn entry probes, in European Planetary Science Conference London, 8-13 September (2013), pp. 8-13

D. Atkinson, J.I. Lunine, A.A. Simon-Miller, S.K. Atreya, W. Brinckerhoff, A. Colaprete, A. Coustenis, L.N. Fletcher, T. Guillot, J.-P. Lebreton, P. Mahaffy, O. Mousis, G.S. Orton, K. Reh, L.J. Spilker, T.R. Spilker, C. Webster, In situ probe science at Saturn, in 11th International Planetary Probe Workshop 1795 (2014), p. 8005

D. Atkinson, A.A. Simon, D. Banfield, S. Atreya, J. Blacksberg, W. Brinckerhoff, A. Colaprete, A. Coustenis, L. Fletcher, T. Guillot, M. Hofstadter, J. Lunine, P. Mahaffy, M. Marley, O. Mousis, T. Spilker, M. Trainer, C. Webster, Exploring Saturn - the Saturn probe interior and atmosphere explorer (SPRITE) mission, in AAS/Division Planetary Scienece Meeting Abstract, vol. 48 (2016), 123.29

S.K. Atreya, A. Crida, T. Guillot T, J.I. Lunine, N. Madhusudhan, O. Mousis, The origin and evolution of Saturn, with exoplanet perspective. ArXiv e-prints (2016). arXiv:1606.04510

S.K. Atreya, M.H. Hofstadter, J.H. In, O. Mousis, K. Reh, M.H. Wong, Deep atmosphere composition, structure, origin, and exploration, with particular focus on critical in situ science at the icy giants. Space Sci. Rev. 216, 18 (2020). https://doi.org/10.1007/s11214-020-0640-8

G. Avice, A. Belousov, K.A. Farley, S.M. Madzunkov, J. Simcic, D. Nikolić, M.R. Darrach, C. Sotin, Highprecision measurements of krypton and xenon isotopes with a new static-mode quadrupole ion trap mass spectrometer. J. Anal. At. Spectrom. 34(1), 104-117 (2019)

K. Biemann, Test results on the Viking gas chromatograph-mass spectrometer experiment. Orig. Life Evol. Biosph. 5(3-4), 417-430 (1974)

K. Biemann, J. Oro, P. Toulmin III., L.E. Orgel, A.O. Nier, D.M. Anderson, P.G. Simmonds, D. Flory, A.V. Diaz, D.R. Rushneck, J.E. Biller, A.L. Lafleur, The search for organic substances and inorganic volatile compounds in the surface of Mars. J. Geophys. Res. 82(28), 4641-4658 (1977)

J.P. Carrico, Applications of inhomogeneous oscillatory electric fields in ion physics, in Dynamic Mass Spectrometry, vol. 3, ed. by D. Price (1972), pp. 1-65

J.E. Chambers, Making more terrestrial planets. Icarus 152, 205-224 (2001)

J.E. Chambers, G.W. Wetherill, Planets in the asteroid belt. Meteorit. Planet. Sci. 36, 381-399 (2001)

A. Chutjian, B.J. Bornstein, D.G. Conroy, A.P. Croonquist, M.R. Darrach, E. Edgu-Fry, G.R. Francis, D.J. Fry, V. Garkanian, M.A. Girard, V.R. Haemmerle, W.M. Heinrichs, R.D. Kidd, J.A. MacAskill, T.M. Rust, R.T. Schaefer, J.L. Thomas, N. Toomarian, M.J. Walch, M. Christensen, D. Demonbrun, R. Vanholden, P.M. Holland, B.J. Shortt, Overview of the vehicle cabin atmosphere monitor, a miniature gas chromatograph/mass spectrometer for trace contamination monitoring on the ISS and CEV. SAE Technical Paper 2007-01-3150 (2007)

A. Chutjian, M.R. Darrach, B.J. Bornstein, A.P. Croonquist, E. Edgu-Fry, D.J. Fry, V. Garkanian, M.A. Girard, V.R. Haemmerle, W.M. Heinrichs, R.D. Kidd, S. Lee, J.A. MacAskill, S.M. Madzunkov, L. Mandrake, T.M. Rust, R.T. Schaefer, J.L. Thomas, N. Toomarian, M.J. Walch, M. Christensen, A. Dawson, D. Demonbrun, R. Vanholden, P.M. Holland, B.J. Shortt, Results from the vehicle cabin atmosphere 
monitor: a miniature gas chromatograph/mass spectrometer for trace contamination monitoring on the ISS and Orion. SAE Technical Paper 2008-01-2045 (2008)

R.O. Fimmel, L. Colin, E. Burgess, Pioneer Venus, in NASA Scientific and Technical Information Branch, NASA SP-461, Washington, D.C. (1983)

D. Gautier, F. Hersant, O. Mousis, J.I. Lunine, Enrichments in volatiles in Jupiter: a new interpretation of the Galileo measurements. Astrophys. J. 550, L227-L230 (2001)

R. Gomes, H.F. Levison, K. Tsiganis, A. Morbidelli, Origin of the cataclysmic Late Heavy Bombardment period of the terrestrial planets. Nature 435, 466-469 (2005)

K.V. Grechnev, V.G. Istomin, L.N. Ozerov, V.G. Klimovitskii, Kosm. Issled. 17, 697 (1979)

J.H. Hoffman, Mass spectrometric measurements of atmospheric composition, in Dynatrend, Inc. Proc. of Outer Planet Probe Technol. Workshop, Sect. 8 (1974), pp. 29-45

M.L. Hoffman (ed.), Applied Mass Spectroscopy Handbook, Chapter 31: J.H. Griffin, T.P. Limero, T. Arkin, C. Richard, Applied Space Applications of Mass Spectrometry, (Wiley, New York, 2010)

J.H. Hoffman, R.R. Hodges, K.D. Duerksen, J. Vac. Sci. Technol. 16, 692 (1979a)

J.H. Hoffman, R.R. Hodges Jr., M.B. McElroy, T.M. Donahue, M. Kolpin, Science 205, 49 (1979b)

P.G.J. Irwin, D. Toledo, R. Garland, N.A. Teanby, L.N. Fletcher, G.S. Orton, B. B'ezard, Detection of hydrogen sulfide above the clouds in Uranus's atmosphere. Nat. Astron. 2, 420 (2018)

P.G.J. Irwin, D. Toledo, A.S. Braude, R. Bacon, P.M. Weilbacher, N.A. Teanby, L.N. Fletcher, G.S. Orton, Latitudinal variation in the abundance of methane $(\mathrm{CH} 4)$ above the clouds in Neptune's atmosphere from VLT/MUSE Narrow Field Mode Observations. Icarus 331, 69 (2019a)

P.G.J. Irwin, D. Toledo, R. Garland, N.A. Teanby, L.N. Fletcher, G.S. Orton, B. B'ezard, Probable detection of hydrogen sulphide $\left(\mathrm{H}_{2} \mathrm{~S}\right)$ in Neptune's atmosphere. Icarus 321, 550 (2019b)

V.G. Istomin, K.V. Grechnev, V.A. Kochnev, Pism'a Astron. ž. 5, 211-216 (1979)

B.G. Jamieson et al., Rev. Sci. Instrum. 78, 065109 (2007)

V.A. Krasnopolsky, Chemical composition of Venus atmosphere and clouds: some unsolved problems. Planet. Space Sci. 54(13-14), 1352-1359 (2006)

C. Lee, E-H. Yang, J.M. Khodadadi, Fabrication, characterization, and computational modeling of a piezoelectrically actuated microvalve for liquid flow control. J. Microelectromech. Syst. 15(3), 686-696 (2006)

W.R. Leo, Techniques for Nuclear and Particle Physics Experiments, 2nd edn. (Springer, Berlin, 1994)

D. Li, K. Jousten, Vacuum 70, 531-541 (2003)

T. Limero, J.T. James, Revalidation of the volatile organic analyzer following a major on-orbit maintenance activity. SAE Technical Paper 2007-01-3220 (2007)

T. Limero, E. Reese, J. Trowbridge, R. Hohmann, J.T. James, Validation of the volatile organic analyzer (VOA) aboard the international space station. SAE Technical Paper 2003-01-2646 (2003)

S.M. Madzunkov, D. Nikolić, Accurate Xe isotope measurement using JPL ion trap. J. Am. Soc. Mass Spectrom. 25(11), 1841-1852 (2014)

S. Madzunkov, J. Simcic, R. Kidd, M.R. Darrach, B. Bae, Recent developments in gas chromatograms and mass spectrometers for crewed and robotic space missions, in 43rd International Conference on Environmental Systems (ICES) Vail, CO, (2013)

S.M. Madzunkov, R.D. Kidd, B. Bae, J. Simcic, S. Schowalter, J. Gill, R. Schaefer, E. Diaz, M.L. Homer, D. Nikolić, M. Darrach, Progress report on the spacecraft atmosphere monitor development model, in 47th International Conference on Environmental Systems, 16-20 July 2017, Charleston, South Carolina (2017). ICES-2017-324

R.E. March, An introduction to quadrupole ion trap mass spectrometry. J. Mass Spectrom. 32(4), 351-369 (1997)

J. Meija, T.B. Coplen, M. Berglund, W.A. Brand, P. De Bièvre, M. Gröning, N.E. Holden, J. Irrgeher, R.D. Loss, T. Walczyk, T. Prohaska, Isotopic compositions of the elements 2013 (IUPAC Technical Report). Pure Appl. Chem. 88(3), 293-306 (2016). https://doi.org/10.1515/pac-2015-0503

O.J. Mousis, D.H. Atkinson, Editorial to the topical collection: in situ exploration of the ice giants: science and technology. Space Sci. Rev. 217, 1 (2021). https://doi.org/10.1007/s11214-020-00772-w

O. Mousis, L.N. Fletcher, J.-P. Lebreton, P. Wurz, T. Cavali'e, A. Coustenis, R. Courtin, D. Gautier, R. Helled, P.G.J. Irwin, A.D. Morse, N. Nettelmann, B. Marty, P. Rousselot, O. Venot, D.H. Atkinson, J.H. Waite, K.R. Reh, A.A. Simon, S. Atreya, N. Andr'e, M. Blanc, I.A. Daglis, G. Fischer, W.D. Geppert, T. Guillot, M.M. Hedman, R. Hueso, E. Lellouch, J.I. Lunine, C.D. Murray, J. O’Donoghue, M. Rengel, A. S'anchez-Lavega, F.-X. Schmider, A. Spiga, T. Spilker, J.-M. Petit, M.S. Tiscareno, M. Ali-Dib, K. Altwegg, S.J. Bolton, A. Bouquet, C. Briois, T. Fouchet, S. Guerlet, T. Kostiuk, D. Lebleu, R. Moreno, G.S. Orton, J. Poncy, Scientific rationale for Saturn's in situ exploration. Planet. Space Sci. 104, 29-47 (2014)

O. Mousis, D.H. Atkinson, T. Spilker, E. Venkatapathy, J. Poncy, R. Frampton, A. Coustenis, K. Reh, J.P. Lebreton, L. Fletcher, R. Hueso, M. Amato, T. Colaprete, F. Ferri, D. Stam, P. Wurz, S. Atreya, S. 
Aslam, D. Banfield, S. Calcutt, G. Fischer, A. Holland, C. Keller, E. Kessler, M. Leese, P. Levacher, A. Morse, O. Munoz, J.-B. Renard, S. Sheridan, F.-X. Schmider, F. Snik, J.H. Waite, M. Bird, T. Cavali'e, M. Deleuil, J. Fortney, D. Gautier, T. Guillot, J.I. Lunine, B. Marty, C. Nixon, G.S. Orton, A. S'anchezLavega, The Hera Saturn entry probe mission. Planet. Space Sci. 130, 80-103 (2016)

O. Mousis, D.H. Atkinson, T. Cavalié, L.N. Fletcher, M.J. Amato, S. Aslam, F. Ferri, J.-B. Renard, T. Spilker, E. Venkatapathy, P. Wurz, K. Aplin, A. Coustenis, M. Deleuil, M. Dobrijevic, T. Fouchet, T. Guillot, P. Hartogh, T. Hewagama, M.D. Hofstadter, V. Hue, R. Hueso, J.-P. Lebreton, E. Lellouch, J. Moses, G.S. Orton, J.C. Pearl, A. Sanchez-Lavega, A. Simon, O. Venot, J.H. Waite, R.K. Achterberg, S. Atreya, F. Billebaud, M. Blanc, F. Borget, B. Brugger, S. Charnoz, T. Chiavassa, V. Cottini, L. d'Hendecourt, G. Danger, T. Encrenaz, N.J.P. Gorius, L. Jorda, B. Marty, R. Moreno, A. Morse, C. Nixon, K. Reh, T. Ronnet, F.-X. Schmider, S. Sheridan, C. Sotin, P. Vernazza, G.L. Villanueva, Scientific rationale for Uranus and Neptune in situ explorations. Planet. Space Sci. 155, 12-40 (2018)

NASA Tech Briefs 40(7), 38 (2016)

H.B. Niemann, D.N. Harpold, S.K. Atreya, Space Sci. Rev. 60, 111 (1992)

H.B. Niemann, S.K. Atreya, G.R. Carignan, T.M. Donahue, J.A. Haberman, D.N. Harpold, R.E. Hartle, D.M. Hunten, W.T. Kasprzak, P.R. Mahaffy, T.C. Owen, S.H. Way, The composition of the Jovian atmosphere as determined by the Galileo probe mass spectrometer. J. Geophys. Res. 103(E10), 22831-22845 (1998)

H.B. Niemann, S.K. Atreya, S.J. Bauer, Space Sci. Rev. 104, 553 (2002)

H.B. Niemann, S.K. Atreya, S.J. Bauer, G.R. Carignan, J.E. Demick, R.L. Frost, D. Gautier, J.A. Haberman, D.N. Harpold, D.M. Hunten, G. Israel, J.I. Lunine, W.T. Kasprzak, T.C. Owen, M. Paulkovich, F. Raulin, E. Raaen, S.H. Way, The abundances of constituents of Titan's atmosphere from the GCMS instrument on the Huygens probe. Nature 438, 779-784 (2005)

D. Nikolić, S.M. Madzunkov, M.R. Darrach, Computer modeling of an ion trap mass analyzer, Part I: low pressure regime. J. Am. Soc. Mass Spectrom. 26(12), 2115-2124 (2015). https://doi.org/10.1007/s13361 $-015-1236-5$

T. Owen, P. Mahaffy, H.B. Niemann, S. Atreya, T. Donahue, A. Bar-Nun, I. de Pater, A low-temperature origin for the planetesimals that formed Jupiter. Nature 402, 269-270 (1999)

T. Owen, P.R. Mahaffy, H.B. Niemann, S. Atreya, M. Wong, Protosolar nitrogen. Astrophys. J. 553, L77-L79 (2001)

W. Spencer, A mass spectrometer concept for identifying planetary atmosphere composition, in Proc. of Outer Planet Probe Technol. Workshop, Sect. 8 (Dynatrend, Inc., Stavanger, 1974), pp. 16-28

T.R. Spilker, D.H. Atkinson, S.K. Atreya, A. Colaprete, L.J. Spilker, Significant science from a Saturn atmospheric entry probe mission, in AGU Fall Meeting Abstracts (2011)

T.R. Spilker, S.K. Atreya, D.H. Atkinson, A. Colaprete, A. Coustenis, Science investigation options with a NASA New Frontiers Program Saturn entry probe mission, in European Planetary Science Congress EPSC 2012-300 (2012)

E. Venkatapathy, D. Ellerby, D. Prabhu, E. Martinez, Saturn atmospheric structure investigation: an assessment of and challenges and recommendations for extending the Galileo approach to future probe missions, in International Workshop on Instrumentation for Planetary Missions, vol. 1683, p. 1129 (2012)

E-H. Yang, C. Lee, J. Mueller, T. George, Leak-tight piezoelectric microvalve for high-pressure gas micropropulsion. J. Microelectromech. Syst. 13(5), 799-807 (2004)

E-H. Yang, C. Lee, J.M. Khodadadi, Development of MEMS-based piezoelectric microvalve technologies. Sens. Mater. 19(1), 001-018 (2007) 